HOU SE PBICES, RENTS. AND INTEREST RATES UNDER COLLATERAL CONSTRAINTS

oscar 5 Arce

and Javid Lopez-Salido.

Documentos de Trabajo. N. 0610

baneo españa

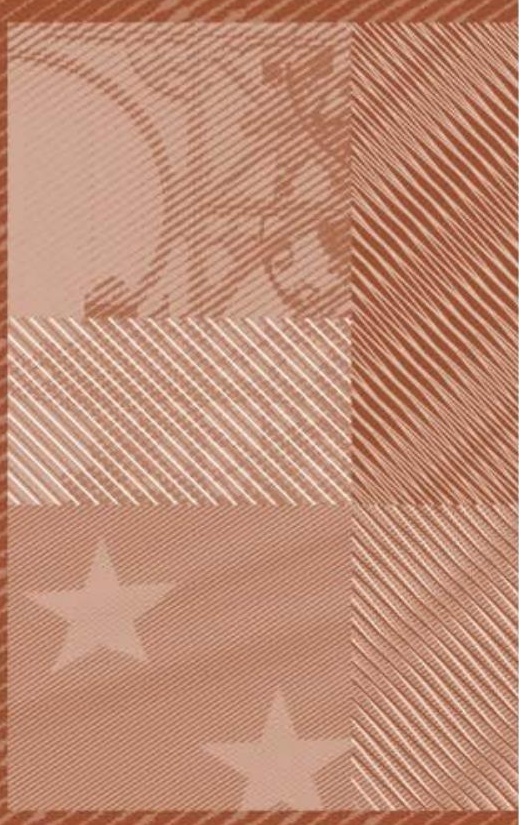


HOUSE PRICES, RENTS, AND INTEREST RATES UNDER COLLATERAL

CONSTRAINTS 


\title{
HOUSE PRICES, RENTS, AND INTEREST RATES UNDER
}

COLLATERAL CONSTRAINTS

\author{
Óscar J. Arce
}

BANCO DE ESPAÑA

J. David López-Salido (*)

BANCO DE ESPAÑA AND CEPR

\begin{abstract}
$\left(^{*}\right)$ We wish to thank Javier Andrés, Juan Ayuso, J. Manuel Campa, Juan F. Jimeno, Claudio Michelacci, Tommaso Monacelli, Roberto Perotti, Rafael Repullo, Fernando Restoy, Maximo Rostagno, Frank Smets, Javier Suárez, an anonymous referee and seminar participants at the Bank of Spain, CEMFI, University of Valencia, IGIER-U. Bocconi, ECB, and San Francisco Fed for useful comments. All errors are ours. Disclaimer: The views expressed herein are those of the authors and not necessarily those of the Bank of Spain. Corresponding author (Arce): Research Department, Bank of Spain. Calle Alcalá, 48, 28014 Madrid (Spain). Phone: +34 913386061. Fax: +34 913385678. e-mail: o.arce@bde.es.
\end{abstract}


The Working Paper Series seeks to disseminate original research in economics and finance. All papers have been anonymously refereed. By publishing these papers, the Banco de España aims to contribute to economic analysis and, in particular, to knowledge of the Spanish economy and its international environment.

The opinions and analyses in the Working Paper Series are the responsibility of the authors and, therefore, do not necessarily coincide with those of the Banco de España or the Eurosystem.

The Banco de España disseminates its main reports and most of its publications via the INTERNET at the following website: http://www.bde.es.

Reproduction for educational and non-commercial purposes is permitted provided that the source is acknowledged.

\section{@ BANCO DE ESPAÑA, Madrid, 2006}

ISSN: 0213-2710 (print)

ISSN: 1579-8666 (on line)

Depósito legal: M.21072-2006

Imprenta del Banco de España 


\begin{abstract}
We develop an OLG model aimed at explaining the joint determination of housing prices, rents, and interest rates, in an environment featuring a positive home ownership bias and individual borrowing limits that generate a mismatch between desired and available funds to finance housing purchases. Individual heterogeneity on this mismatch gives rise to three different types of households: renters, landlords (i.e. buy-to-let investors, who provide the stock of houses for rent) and home buyers who do not participate in the rental market. We investigate the conditions under which two alternative stationary equilibria may coexist: (i) a low valuation equilibrium (LVE) in which landlords do not exhaust their borrowing limits; and (ii) a high valuation one (HVE) where every household is financially constrained the time of purchasing its housing stock. In a HVE (relative to the LVE) the volume of buy-to-let investment, the price-to-rent ratio and the housing price are higher while the interest rate is lower. Due to binding borrowing constraints, in a HVE further reductions in the interest rate only bear a positive networth effect through a reduction of the cost of repaying outstanding mortgaged debt, which fuels future availability of funds, thus sustaining the higher demand for credit. More generally, coexistence of both types of equilibria provides a rationale for the existence of speculative paths from a LVE to a HVE.
\end{abstract}

Keywords: price-to-rent ratio, collateral constraints, buy-to-let investment, multiple equilibria. JEL classification: G21, R21, R31 


\section{Introduction}

Buying a house is one of the most important economic decisions made by many households over their life. The fact that a house is both a good, in that it produces valuable housing services, and an asset, in the sense that it is a durable good which can be resold in a future date, certainly tends to enlarge the list of factors relevant for that decision. This dual (good-asset) nature of a house implies, on the one hand, that one may consume housing services without need to become a home owner if a rental market exists, and, on the other, it allows for the possibility that some individuals find convenient to purchase houses as a pure investment, seeking to obtain benefits in the form of capital gains and dividends (i.e. rents). Moreover, irrespectively of the final destination of a house, whether to be occupied by the owner or used as an investment instrument, a buyer will take into consideration the opportunity cost of the funds used in that operation, as captured by the return of alternative investment opportunities, and the effective cost of borrowing funds to finance it. Thus, the interest rate together with the housing and rental prices are certainly first-order importance factors in guiding both the housing services consumption and asset accumulation choices.

In this paper we argue that our understanding of the interactions between the three prices (and the corresponding markets) just mentioned can be largely improved by incorporating into the analysis some frictions that may be present in both the rental and credit markets. In the first case, the presence of informational asymmetries or tax distortions may create a bias against renting housing services, as emphasized in the previous literature. In the second, the existence of collateral restrictions, perhaps due to lack of commitment related problems, may act as a barrier to housing ownership by limiting the maximum amount of funds that an individual can borrow.

To develop our arguments we build up a simple overlapping generations (OLG) model, where each household lives for three periods. A household derives utility from consumption and housing services, that can be acquired either by owning a house or by renting it. In each period there coexist three types of generations in the economy: (i) a group of households making their tenure and the corresponding financing decisions; (ii) another group repaying mortgages and building up stocks of financial assets aimed at financing future consumption later in their life; this group provides the bulk of loanable savings in the economy; and, (iii) a group consuming the proceeds of previous savings. We make operative the friction in the rental market by assuming that housing services provided by owner-occupied dwellings are untaxed, while services obtained through renting are subject to taxation, as in Poterba (1984). ${ }^{1}$ As for the financial friction, we consider a credit constraint in line with the one highlighted by Kiyotaki and Moore (1997) and assume that households can only borrow up to a fraction of the value of their house, which here is the only collateralizable asset. The separation between the good- and the asset-dimensions is accomplished by allowing households in the first generation above to participate in either side of the rental market, i.e. as renters or landlords. Renters consume an amount of housing

\footnotetext{
${ }^{1}$ Henderson and Ioannides (1983) focus on maintenance and utilization costs as a prime source of a bias towards ownership.
} 
services above the one produced out of their own stock of housing, while the opposite is true for landlords who hold houses in their portfolio not to occupy them, but rather to let and, afterwards, sell them out. Thus, the way a household accumulates a housing stock as a pure asset in our economy is through a buy-to-let-to-sell investment (or BLS, for short).

Borrowing limits, when binding, generate a mistmatch between desired and available funds to finance housing purchases. We consider the existence of idiosyncratic heterogeneity on this mismatch such that in equilibrium the multiplier on the credit constraint varies across households or, in plain words, some households will be "more constrained" than others. This gives rise to individual heterogeneity regarding both housing tenure (i.e. renting versus purchasing) and financial position (constrained or unconstrained). In particular, we show that in equilibria in which the rental market is operative, there coexist three groups of households: (i) renters, (ii) landlords, and (iii) home buyers that do not participate in either side of the rental market. This segmentation arises as an endogenous outcome, in the sense that a household falls into a particular group depending on its specific borrowing limit but also on the equilibrium price-to-rent ratio.

As the equilibrium price-to-rent ratio is always greater than unity, renting allows households with a lower borrowing limit to consume a larger amount of housing services than if they were to rely only on ownership. In this sense, we find that, ceteris paribus, more renting raises the overall demand for housing services. Then, a higher price-to-rent ratio raises the volume of resources devoted to demand rental services and hence pushes the housing price up. Also, as a higher price-to-rent ratio tantamounts to a relative fall in dividends (rents), it leads landlords to reduce their BLS investments and to increase their own consumption of housing services, reinforcing the previous inflationary effect on prices.

A critical feature of the model is that, in equilibrium, all landlords are simultaneously credit constrained or unconstrained. We show that for sufficiently low values of the price-to-rent ratio every landlord is unconstrained and a non-arbitrage condition that equates the housing price to the rental price (net of taxes) discounted at the cost of funds rate is part of the equilibrium. However, beyond a sufficiently high price-to-rent ratio, all landlords find optimal to exhaust their borrowing limit. In that case, the equilibrium condition that links prices, rents and interest rates is not isomorphic to the previous case, as a reflection of the fact that investing in houses yields a return higher than the cost of external funding (i.e. the interest on mortgages). Indeed, an important feature of the model is that, under some conditions, there exist two different steady state equilibria for a given set of fundamentals. A low valuation equilibrium (LVE, henceforth) in which the landlords do not to exhaust their borrowing limit, and a high valuation equilibrium (HVE, henceforth), in which every household is constrained at the time of purchasing its housing stock. We show that housing prices, the price-to-rents ratio, the amount of debt and the volume of BLS purchases are lower in a LVE than in a HVE, while interest rates and rents are lower in a HVE. Further, due to the amplification mechanisms arising from the mutual feedback between housing prices, the value of collateral and the households' borrowing capability, we argue that relaxing the collateral constraint (say, as the result of a process of financial liberalization) tends to amplify the differences across the two equilibria just mentioned. 
As recently pointed out by Caballero, Farhi and Hammour (2005), one of the central questions in the analysis of the conditions that may allow for the coexistence of low and high asset valuation steady states is the following: how can an economy have a low interest rate in a high asset-price equilibrium when it requires more funding to be sustained? These authors emphasize a well known mechanism present in some OLG models with capital accumulation, namely, that movements in interest rates may generate sufficiently strong negative income or wealth effects, so that for a certain range of the interest rates, the aggregate supply of funding becomes downward sloped, thus allowing for multiple steady states. Here we stress that wealth effects may also be helpful to understand episodes of large housing price increases and low interest rates, as those experienced recently by some OECD countries. In our set up what generates such wealth effect is the presence of borrowing limits. In a HVE, as the interest rate is sufficiently low such that all agents find optimal to use all their borrowing capacity at the time of making the decision of buying a house, the aggregate demand for credit becomes insensitive to the interest rate. However, further reductions in the interest rate will increase the net worth of borrowers through a reduction of the cost of repaying their outstanding debt. In our model this extra wealth will be partially devoted to increase the amount of savings of older generations that provide the required funding to sustain a HVE. ${ }^{2}$ But the previous steady state can coexist with a LVE where the wealth effect just described will be weaker than in the neighborhood of a HVE, since the fact that landlords are unconstrained implies that a reduction in the interest rates does not only exert a positive wealth effect for borrowers but also a relative price effect (i.e. an increase in the price-to-rent ratio) that runs in the opposite direction. Hence, except under rather extreme circumstances, in a LVE the aggregate supply of funding is upward sloped and the resulting equilibrium interest rates are higher than in the HVE.

Although for most part of the paper we confine our analysis to the (co)existence of stationary equilibria, we think that the model constitutes a useful first step in shedding light on the relative importance of 'expectations' and 'fundamentals' in understanding a number of stylized facts observed in some episodes of rapid housing prices increases, including the positive correlation of the equilibrium housing price with the price-to-rent ratio, the volume of housing purchases for investment motives, including BLS investments, the debt-to-income ratio of those households purchasing homes, and the negative correlation between housing prices and real interest rates. Along the lines of that methodological approach it is possible to understand that a speculative path from a LVE to a HVE may arise as an equilibrium outcome, without need to resort to explanations based only on irrational individual decisions. ${ }^{3}$

There is a growing number of empirical studies that have tried to link the evolution of housing prices with fluctuations in some of the underlying fundamentals, including changes in family incomes, demographic trends, environmental restrictions on building and, more importantly, on the fall in both the short- and long-run interest rates. Regarding the recent housing

\footnotetext{
${ }^{2}$ In a companion paper, Arce and López-Salido (2006), we develop an open economy version of the model where we investigate the role of external saving and banking competition.

${ }^{3}$ In this sense, our paper is connected to the seminal analyses develop by Krugman (1991) and Matsuyama (1991), and more recently rescued by Caballero et al. (2005).
} 
booms, a typical finding is that housing prices show symptoms of overvaluation. ${ }^{4}$ That is, even after accounting for the benign evolution of the aforementioned fundamentals, it is difficult to rationalize the magnitude of the recent run up in prices. Indeed, the rapid increase in housing prices has led some commentators to warn about a possible bubble-like scenario, a perspective that puts some doubts on the likelihood of a smooth adjustment in the aftermath of an eventual adverse shock. ${ }^{5}$ Brunnermeier and Juillard (2005), using an asset-pricing valuation approach à la Campbell and Shiller (1988) that exploits some intertemporal links between prices, rents and interest rates, argue that deviations from rational expectations, in the form of money illusion, can explain the recent sharp increases in prices. ${ }^{6}$ In contrast, Himmelberg, Mayer, and Sinai (2005) claim that it is possible to account for the evolution of housing prices by properly constructing the right measure of the annual user cost of holding a dwelling. These authors argue that prices are more sensitive to interest rates when these are already low, specially in cities where the long-run rate of house price growth is high. Our theoretical model is closer in spirit to this latter empirical view, since it does not introduce any form of irrationality.

Our paper is also related to some theoretical literature that has emphasized the effects of borrowing limits on housing prices dynamics. Stein (1995) shows that the existence of a downpayment requirement at the time of purchasing a house may contribute to explain the significantly high correlation between housing prices and volume of transactions. Ortalo-Magné and Rady (2005) build up a life-cycle model that features a property ladder in order to investigate how changes in the income of young households, a large proportion of which are credit constrained, may give rise to price overreaction. Our model differs from both in that we place special emphasis on the interaction between the rental and housing markets, while the possibility of renting housing services is inessential for these two analyses. We also endogenize the equilibrium determination of the interest rate, that is, while these two papers treat the return on the investment on housing as endogenous, the return of other assets is set exogenously. Gervais (2002) explicitly analyzes how tax distortions affect the tenure decision (housing vs. renting) in a dynamic model. Yet, we depart from him in two important dimensions. First, in his analysis the dynamic of housing prices is absent since the focus is mainly on taxation and capital accumulation. ${ }^{7}$ Second, in Gervais, BLS investments are not subject to downpayment requirements. Here we impose these requirements in a symmetric way, that is, in our economy agents are subject to borrowing limits, no matter what the final destination of their purchases (owner occupancy or BLS) is.

Our paper departs from recent papers by Iacoviello (2005) and Davis and Heathcote (2005) that analyze the role of the housing sector on business cycle dynamics. In particular, the

\footnotetext{
${ }^{4}$ Some recent examples include (within parentheses, the country under study) Ayuso and Restoy (2005, 2006; Spain), Duca (2005; US); European Central Bank (2006; Euro area), and OECD (2006; OECD countries).

${ }^{5}$ See, for instance, Baker (2005), Case and Shiller (2004), The Economist (2005a, b, c), Leamer (2003), and Morris and Wang (2006).

${ }^{6}$ McCarthy and Peach (2004) also emphasize the role of diminishing nominal interest rate as a prime cause of the upsurge in housing prices in the U.S.

${ }^{7}$ He assumes that houses and consumption goods are produced using identical technologies, which in his model implies that the relative price is always 1. A similar assumption on the exogeneity of the relative price is made in Peterson (2004), Chambers et al. (2005), Jeske and Krueger (2005), Li and Yao (2005), and Yao and Zhang (2005).
} 
first one emphasizes the role of collateral constraint as an amplifying mechanism of economic fluctuations in an otherwise New Keynesian model where the role of monetary policy is also analyzed. Davis and Heathcote (2005) use a neoclassical multisector growth model where the housing sector requires land in addition to new structures. The model can explain the positive comovements of hours across sectors as well as the higher volatility of construction in response to technology shocks. None of these papers, however, examines the role of household heterogeneity along both the rental and the housing markets as well as the importance of the borrowing limits as to endogenously sustain the existence of a high valuation equilibrium.

The structure of the paper is as follows. In Section 2 we lay out a simple OLG environment, characterize the solution of the utility maximization problem faced by the households and describe some of the main features of the equilibrium market segmentation. In Section 3 we describe the housing and rental markets across alternative steady states (LVE and HVE). In Section 4 we analyze the credit market and the long-run funding mechanism that may sustain a HVE. In section 5 we investigate the conditions for the existence and coexistence of stationary equilibria and study how changes in the downpayment and taxes affect these conditions. Section 6 present the main conclusions of the paper. An Appendix contains some of the formal proofs.

\section{The model}

\section{$2.1 \quad$ Timing and assumptions}

In our model time is discrete and there is a continuum of households, each of which live for three periods. We assume that after dying, each household is replaced by an identical newly born one, so that population remains constant. Households derive utility from consumption, $c$, and the flow of housing services that can be acquired either by owning a house or by renting it; $h$ and $s$, respectively. These two tenure alternatives, for simplicity, are assumed to provide perfectly substitutable services in an amount equal to the size of the dwelling. Moreover, the stock of houses is thought to be perfectly divisible and households can simultaneously enjoy housing services from owing a house and renting another. ${ }^{8}$

In the first period of life, each household receives an exogenous endowment of consumption goods, $z \in \mathcal{Z}=(0, Z]$, which is distributed independently and identically according to a continuos and differentiable cumulative distribution function $F(z)$ on $\mathcal{Z}$. The households decide the amount of consumption, housing services, financial assets and debt. In particular, a household may save by purchasing houses or financial assets (henceforth, deposits). Some households will also engage in BLS strategies, so that their desired stock of houses may be larger than the one being actually occupied by them. As for the debt decision, we assume that only

\footnotetext{
${ }^{8}$ These assumptions, perfect divisibility and non-excludability in the two forms of tenure, greatly simplify the analysis by eliminating non-convexities in the household's choice set. Indeed, the objective of the household's problem is concave and the constraint set convex, and hence the first order conditions are necessary and sufficient. In a companion paper, Arce and López-Salido (2006), we relax this assumption by forcing households to choose between either being renters or homeowner which renders the choice set non convex. The basic results remain unchanged at the cost of some more cumbersome algebra.
} 
collateralized debt is available, and we impose the existence of borrowing limits at the time of purchasing a house. Specifically, a minimum downpayment proportional to the value of the house is required, and critically, such a restriction applies irrespectively of the purpose of the purchase, i.e. regardless of whether the house will be occupied by the owner or supplied in the rental market.

Regarding the specification of the downpayment we consider that it is a monotonically decreasing function of the household's endowment. We think of this assumption as a pragmatic modelling device aimed at capturing individual heterogeneity in the degree of mismatch between desired (i.e. in the absence of a downpayment requirement) and available funds to finance housing purchases. ${ }^{9}$ In order to derive such a household-specific mismatch as an endogenous outcome we would have to consider non-homothetic preferences, individual specific dynamic income patterns (as in Gervais 2002), or heterogenous initial collateralizable endowments (say, bequests in the form of houses, as in Stein 1995). Our assumption allows us to achieve the same outcome in terms of delivering the aforementioned mismatch in a way that preserves analytical tractability.

As for the source of home ownership, we follow Poterba (1984) in assuming that housing services provided by owner occupied housing is untaxed, while services obtained through renting are subject to taxation. In particular, we consider that landlords pay a tax proportional to the rental income, as in Berkovec and Fullerton (1992).

In the second period, households decide how to allocate their net worth (stock of houses acquired in the previous period and deposits net of debt repayments) between consumption and deposits. Finally, in the last period they consume all their financial wealth.

Taking together, these assumptions deliver a simple OLG structure that allows us to focus on equilibria that resemble the fact that early in life households borrow to buy houses and, as time goes by, agents who have already acquired houses start to increase their holdings of financial assets. Such a life-cycle portfolio composition pattern has been extensively documented in several recent empirical studies (see e.g. Flavin and Yamashita (2002), Campbell and Cocco (2005), Fernández-Villaverde and Krueger (2005), Li and Yao (2005), Yang (2005), and Yao and Zhang (2005)).

It is worth noting that the timing of decisions just described embeds some assumptions that are more restrictive than needed to generate the aforementioned life cycle facts. In particular, the model structure implies that the households sell their entire stock of houses in the second period to the newly born generation, and that they do not BLS at that time. By keeping this group of households out of the housing and renting markets, we circumvent the problem of having to deal with the segmentation in the housing-renting and credit markets for the generation born in the previous period. ${ }^{10}$ Indeed, as we will show later in detail, the critical

\footnotetext{
${ }^{9}$ Evidence supporting the effects of individual characteristics, including wealth and income, on the conditions of access to credit is provided by Linneman and Watchter (1989) and Haurin, Hendershott and Wachter (1996).

${ }^{10}$ In the model we solve below, we find equilibria in which the members of the generation born at the current period are grouped into three distinct segments. Thus, relaxing the assumptions about the endowment, and housing and rental market participation of the generation born in the preceding period would potentially lead to
} 
feature of this structure is that it retains the idea that a household first accumulates wealth in the form of housing stocks and afterwards tends to save in the form of more liquid (loanable) assets, which here happens in the second period.

From a different perspective, not so closely linked to life-cycle patterns as those just described, our OLG structure would be consistent with an economy in which, even when the households would ideally wish to adjust the size of their real estate holdings continuously, they do not do so and at some points in time they rather choose to adjust the size of their financial assets portfolios. Thus, instead of modelling explicitly some frictions in the housing and rental markets that could justify such an asset accumulation pattern (e.g. transaction costs, minimum house-size constraints, non-Walrasian elements, etc.), we employ these seemingly restrictive assumptions that keep the model analytically tractable. ${ }^{11}$

In sum, in our set up at every period there coexist three type of 'generations': a group of households making their tenure decisions (an their funding scheme), another group repaying mortgages and building up stocks of financial assets aimed at financing future consumption later in their life; and a last group consuming the proceeds of previous savings. Thus, we think of three periods as the simplest OLG structure that captures the interactions between the different groups of household just described.

\subsection{The households' problem}

Each household born at time $t$ maximizes the following flow of utility

$$
\log \left(c_{t}^{y}\right)+\beta\left[\log \left(c_{t+1}^{m}\right)+\log \left(h_{t+1}+s_{t+1}\right)\right]+\beta^{2} \log \left(c_{t+2}^{o}\right)
$$

subject to the following set of constraints

$$
\begin{gathered}
c_{t}^{y}+p_{t} h_{t+1}+\left[p_{t}-(1-\tau) q_{t}\right] g_{t+1}+q_{t} s_{t+1}+a_{t+1}^{y}-b_{t+1} \leq z \\
c_{t+1}^{m}+a_{t+2}^{m} \leq p_{t+1}\left(h_{t+1}+g_{t+1}\right)+\left(1+r_{t+1}\right)\left(a_{t+1}^{y}-b_{t+1}\right) \\
c_{t+2}^{o} \leq\left(1+r_{t+2}\right) a_{t+2}^{m} \\
b_{t+1} \leq(1-\theta(z)) p_{t}\left(h_{t+1}+g_{t+1}\right) \\
c_{t}^{y} \geq 0 ; c_{t+1}^{m} \geq 0 ; c_{t+1}^{o} \geq 0 ; h_{t+1} \geq 0 ; g_{t+1} \geq 0 \\
s_{t+1} \geq 0 ; \quad a_{t+1}^{y} \geq 0 ; a_{t+2}^{o} \geq 0 ; b_{t+1} \geq 0
\end{gathered}
$$

where $\beta$ is the discount factor; $c$ represents consumption and the superscripts $y, m$, and $o$, stand for young, middle-aged and old, respectively; $a$ represents non-housing assets -deposits-, $b$ is the amount of collateralized debt, $g$ represents the amount of BLS housing, $p$ is the housing price, $q$ is the rental price (both $p$ and $q$ are given in terms of consumption goods), and $r$ is the interest

equilibria in which nine segments coexist. While such a sort of analysis is interesting in its own, since it would allow us to add 'property-ladder' considerations into our general equilibrium framework, it goes beyond the scope of this paper.

${ }^{11}$ Indeed, intermittent individual market participation is not an uncommon assumption in general equilibrium models with collateral constraints (see e.g. Kiyotaki and Moore $(1997,2005)$ ). 
rate. $^{12}$

When young, see (2), households receive an endowment of consumption goods and decide on the amount of housing and non-housing consumption, and on their financial portfolio (debt and deposits). They may obtain housing services by either buying $(h)$ or renting $(s)$ a dwelling. Further, a household may supply houses in the rental market, in which case, it is assumed that the rental income is taxed at a rate $\tau$. Note that we are assuming the timing convention that newly purchased houses, $g$, can be rented out in the same period. Thus, there are not nonoccupied houses. According to expression (5) the borrowing limit is such that the household must satisfy a minimum downpayment requirement, so that the maximum amount of debt can not be larger than a fraction $1-\theta(z)$ of the value of its housing purchases. Further, this requirement applies irrespectively of the use of the dwelling (i.e. owner occupancy or renting). In the second period, households liquidate their housing stock, repay debt (inclusive of interest charges), consume goods and save in the form of deposits (see (3)). Finally, when old, they consume the proceeds of their financial holdings (see (4)).

The following assumptions ensure that we capture the scenario outlined above.

Assumption A1 (Taxation bias) $\tau>0$.

Assumption A2 (Heterogenous financial mismatch) $\theta(z)=\theta+\sigma(z)$, with $\sigma_{z}<0$, and $0<\theta+\sigma(z)<1$.

This last assumption captures in a simple way the idea that some households may be more constrained than others, i.e. that the multiplier associated to the borrowing constraint (5) varies across households.

\subsection{Interior equilibrium}

Before characterizing the equilibrium of this economy, we will briefly refer to the supply of housing and the actions of the government. First, as in Poterba (1984), Stein (1995), and, more recently, Ortalo-Magné and Rady (2005) we assume a fixed supply of houses. Some of our main results are completely independent of this assumption. Others, such as the qualitative long-run behavior of the housing prices will hold as long as that supply is not fully elastic. Second, the government consumes all the proceeds obtained from the taxation of the renting activities.

This economy can be described by household's preferences, the discount factor, the downpayment, the tax rate, the fixed supply of houses, and the support of the distribution over the initial endowment. We will look at interior equilibria where the rental market is operative.

Definition 1 (Equilibrium) A perfect foresight competitive interior equilibrium for this economy is a set of allocations, $\left\{c_{t}^{y}(z), c_{t}^{m}(z), c_{t}^{o}(z), a_{t+1}^{y}(z), a_{t+1}^{m}(z), b_{t+1}(z), h_{t+1}(z), s_{t+1}(z), g_{t+1}(z)\right\}$,

\footnotetext{
${ }^{12}$ Notice that mortgages and deposits interest rates are equal. This may also be consistent with a richer tax structure where interest rate payments are fully tax-deductible in which case there is no gap between net rates of deposits and mortgages (see Gervais (2002)).
} 
for all $z \in \mathcal{Z}$, price and interest rate sequences $\left\{p_{t}, q_{t}, r_{t}\right\}_{t=0}^{\infty}$, and a tax rate $\tau$, such that (i) households maximize their utility (1) subject to constraints (2)-(6) given the sequences $\left\{p_{t}, q_{t}, r_{t}\right\}$ and the government policy; (ii) the government satisfies its flow of funds constraint period by period, i.e. tax collection is equal to government spending; and (iii) all markets clear.

\subsection{Markets segmentation}

In this section we first distinguish different groups of households according to their tenure choice, and we then introduce several lemmas to characterize in detail how the housing, rental, and credit markets are accordingly segmented. We start with the following definition.

Definition 2 (Types of households). (i) Renter, if $s_{t+1}>0$ and $g_{t+1}=0$, (ii) Buyer, if $g_{t+1}=s_{t+1}=0$, (iii) Landlord, if $s_{t+1}=0$ and $g_{t+1}>0$.

For the sake of the exposition we write below the first order conditions of the maximization problem solved by a household born at time $t$ :

$$
\begin{aligned}
& c_{t}^{y}:\left(c_{t}^{y}\right)^{-1}=\lambda_{t} \\
& s_{t+1}:-\lambda_{t} q_{t}+\beta\left(h_{t+1}+s_{t+1}\right)^{-1}+\varphi_{t+1}^{s}=0 \\
& a_{t+1}^{y}:-\lambda_{t}+\beta \lambda_{t+1}\left(1+r_{t+1}\right)+\varphi_{t+1}^{a}=0 \\
& b_{t+1}: \lambda_{t}-\beta \lambda_{t+1}\left(1+r_{t+1}\right)+\varphi_{t+1}^{b}-\mu_{t+1}=0 \\
& h_{t+1}:-\lambda_{t} p_{t}+\beta\left(h_{t+1}+s_{t+1}\right)^{-1}+\beta \lambda_{t+1} p_{t+1}+\varphi_{t+1}^{h}+(1-\theta) p_{t} \mu_{t+1}=0 \\
& g_{t+1}:-\lambda_{t}\left[p_{t}-(1-\tau) q_{t}\right]+\beta \lambda_{t+1} p_{t+1}+\varphi_{t+1}^{g}+(1-\theta) p_{t} \mu_{t+1}=0 \\
& a_{t+2}^{m}:-\lambda_{t+1}+\beta \lambda_{t+2}\left(1+r_{t+2}\right)+\varphi_{t+2}^{a}=0 \\
& c_{t+1}^{m}::\left(c_{t+1}^{m}\right)^{-1}=\lambda_{t+1} \\
& c_{t+2}^{o}:\left(c_{t+2}^{o}\right)^{-1}=\lambda_{t+2}
\end{aligned}
$$

where $\lambda$ 's are the Lagrange multipliers associated to restrictions (2)-(4), $\mu$ is the Lagrange multiplier associated to the borrowing constraint (5), and the different $\varphi^{\prime}$ s correspond to the Lagrange multipliers of the non-negativity constraints in (6) and (7). The discussion of these first order conditions is addressed within the lemmas below.

Lemma 1 (Segmentation I) All landlords are simultaneously either constrained or unconstrained.

Proof. We prove it by contradiction. Let us start by assuming that there is (at least) an unconstrained landlord. Hence, for that landlord it follows that $\mu_{t+1}=0$ and $\varphi_{t+1}^{g}=0$. Then from (10) and (11) it follows that $\varphi_{t+1}^{a}+\varphi_{t+1}^{b}=0$, and hence $\varphi_{t+1}^{a}=\varphi_{t+1}^{b}=0$, i.e. for unconstrained households the non-negativity constraints on deposits and loans are not binding. Then, using (10) and (13) it follows that,

$$
\frac{p_{t+1}}{p_{t}-(1-\tau) q_{t}}=1+r_{t+1}
$$


We now analyze a situation where there is (at least) a constrained landlord. For this landlord, $\varphi_{t+1}^{g}=0$ and $\mu_{t+1}>0$. Then from expression (5) we learn that $\varphi_{t+1}^{b}=0$. Combining (10) and (11), it follows that $\varphi_{t+1}^{a}>0$; i.e. if the borrowing constraint is binding then $a_{t+1}^{y}=0$ and $\frac{\lambda_{t}}{\beta \lambda_{t+1}}>1+r_{t+1}$. Hence, its intertemporal marginal rate of substitution must be greater than the cost of funds. ${ }^{13}$ Next, by combining (11) and (13) it follows that

$$
\frac{p_{t+1}}{p_{t}-(1-\tau) q_{t}}>1+r_{t+1}
$$

which clearly contradicts (17).

The interpretation of (17) is straightforward. Any unconstrained household must necessarily be indifferent between holding deposits or BLS, the return of which includes capital gains due to any difference between the buying and selling prices, plus rents. Yet, from expression (18) it follows that if the cost of external funds goes below the return of the BLS investment, then landlords optimally exhaust their borrowing capacity.

Lemma 2 (Segmentation II) Under assumption A1 the following results hold: (a) $g_{t+1}$. $s_{t+1}=0$, (b) $h_{t+1}>0$; and, if the borrowing constraint is not binding, (c) $s_{t+1}=0$.

Proof. (a) Straightforward. This implies that no household would optimally put itself simultaneously on both sides of the (tax-distorted) rental market.

(b) Let us assume that $h_{t+1}=0$ (i.e. $\varphi_{t+1}^{h}>0$ ). Hence $s_{t+1}>0$ and $g_{t+1}=0$. Given that this household has no collateral then, $b_{t+1}=0$ and $a_{t+1}^{y}>0$; thus the relevant FOCs are (9), (10), and (12). Now, according to lemma 1 we consider two cases:

(i) all landlords are unconstrained. Thus, from (17) we can write

$$
p_{t+1}-\left(1+r_{t+1}\right)\left(p_{t}-q_{t}\right)=\left(1+r_{t+1}\right) \tau q_{t}>0
$$

Now combining (9), (10), and (12) it follows that

$$
p_{t+1}-\left(1+r_{t+1}\right)\left(p_{t}-q_{t}\right)=-\varphi_{t+1}^{h}>0
$$

and the last inequality, which follows from (19), is inconsistent with $\varphi_{t+1}^{h}>0$.

(ii) all landlords are constrained. Thus, from (18) we can write

$$
p_{t+1}-\left(1+r_{t+1}\right)\left(p_{t}-q_{t}\right)>\left(1+r_{t+1}\right) \tau q_{t}>0
$$

which again leads to contradiction. The role of the tax-induced ownership-bias is clear in driving this result since only in the corner case of no tax distortion, a household may optimally decide not to buy.

(c) If the household is not constrained, then according to (17) the cost for a tenant of renting is $q_{t}=\frac{1}{(1-\tau)}\left[p_{t}-\frac{p_{t+1}}{1+r_{t+1}}\right]$, which for $\tau>0$ it is always greater than the cost of buying the same

\footnotetext{
${ }^{13}$ Notice that the last inequality applies for any constrained household, and not just for landlords. To see this, recall that the above argument only requires $\mu_{t+1}>0$.
} 
unit of housing services, i.e. $p_{t}-\frac{p_{t+1}}{1+r_{t+1}}$. The intuition is straightforward, if the household is not constrained it will never get services in the distorted rental market, since these services could be produced by itself by exploiting the borrowing capacity and, hence, avoiding the tax.

In sum, from this lemma we learn that a household that optimally decides to demand a positive amount of rental services must simultaneously be an owner, i.e. there are no pure renters, since it is less costly to produce housing services out of the own housing stock than renting them. Yet, the fact that some households do optimally choose to rent shows that ownership is costly in terms of the extra resources needed to buy rather than rent a given dwelling. Not surprisingly, as formally stated in this lemma, only households exhausting their borrowing capability will demand rental units. In this sense, the presence of a borrowing limit is the raison d'être for an operative rental market in the present environment. The following lemma, however, shows that the presence of binding collateral constraints may not be sufficient to generate a positive demand for renting.

Lemma 3 (Segmentation III) Under assumptions A1 and A2 there exist a non-empty set of constrained households such that $g_{t+1}=s_{t+1}=0$.

Proof. We first identify the household with the lowest income, which we denote by $z_{1}$, such that at time $t$ it optimally chooses not renting, i.e. $s_{t+1}(z)=0 \forall z \geq z_{1}$. Then, we identify the household with the highest income, $z_{2}$, such that it optimally chooses a zero supply of renting services, i.e. $g_{t+1}(z)=0 \forall z \leq z_{2}$. We finally show that $z_{2}>z_{1}$.

In the Appendix we describe the individual demand function associated to different kind of households in this economy. In order to pin down $z_{1}$, we use that $s_{t+1}\left(z_{1}\right)=\gamma \beta\left(\frac{1}{q_{t}}-\frac{1+\beta}{\theta\left(z_{1}\right) p_{t}-q_{t}}\right) z_{1}=$ 0 , where $\gamma \equiv(1+\beta)^{-2}$ and $s_{t+1}\left(z_{1}\right)$ corresponds to the demand for renting services of the household with endowment $z_{1}$. Using this equality, we can write

$$
\theta\left(z_{1}\right)=(2+\beta) \frac{q_{t}}{p_{t}}=\frac{(2+\beta)}{\eta_{t}}
$$

where $\eta_{t} \equiv \frac{p_{t}}{q_{t}}$ is the price-to-rent ratio. To compute $z_{2}$, we proceed as before distinguishing two cases: every landlord is (i) unconstrained, or (ii) constrained.

(i) We take an unconstrained landlord and obtain the maximum amount of BLS investment such that this landlord reaches its borrowing limit. To pin down the pivotal household, separating the group of (constrained) buyers and unconstrained landlords, we then impose that such a maximum $g$ is equal to zero. Formally, we notice that for this household the following constraints hold: $a_{t+1}^{y}\left(z_{2}\right)=0$, and $b_{t+1}\left(z_{2}\right)=\left(1-\theta\left(z_{2}\right)\right) p_{t} h_{t+1}\left(z_{2}\right)$; which can be used to find that:

$$
\theta\left(z_{2}\right)=\frac{(2+\beta)(1-\tau)}{\eta_{t}}
$$

(ii) When every landlord is constrained, we use the following condition:

$$
g_{t+1}\left(z_{2}\right)=\gamma \beta\left[\frac{1+\beta}{\theta\left(z_{2}\right) p_{t}-(1-\tau) q_{t}}-\frac{1}{(1-\tau) q_{t}}\right] z_{2}=0
$$


which allows us to obtain

$$
\theta\left(z_{2}\right)=\frac{(2+\beta)(1-\tau)}{\eta_{t}}
$$

Interestingly, we learn that, irrespective of whether case (i) or (ii) holds, the expression that allows us to identify the pivotal household $z_{2}$ is the same. Finally, from assumptions A1 and A2 and the thresholds expressions (21) and (22) it follows that: $\theta\left(z_{1}\right)<\theta\left(z_{2}\right) \Rightarrow z_{2}>z_{1}$.

From the previous result, as long as $\tau>0$, there is a fraction of households that do not participate in the rental market, and we refer to these households as buyers (Definition 1). Several comments are in order. First, these households find optimal to exhaust their borrowing limits to finance the purchase of their homes. This is so since, on the one hand, they face a borrowing limit low enough so as to prefer not to demand housing services in the tax-distorted rental market; but on the other hand, such a limit is sufficiently tight so as to preclude them from investing in BLS. Second, from (21) and (22) it follows that the measure of households that demand (supply) renting services increases (decreases) with the relative price $\eta_{t}$.

In sum, the previous lemmas state how the households' tenure and funding decisions are affected by the interaction between relative prices and downpayment requirements. A general interpretation of this link can be provided along the lines of the good versus asset distinction mentioned earlier. In equilibrium there will be households willing to demand renting services due to the existence of borrowing limits. Absent these, no one would participate in that market, given the tax distortion. In particular, a household will be a renter whenever there is a substantial deviation between a the desired amount of housing services and its available funds (as a result of tight borrowing limits), thus optimally reducing ownership (which here has an asset-good consideration) in favor of renting to enjoy a larger amount of housing services (which here has a good consideration). However, if the household has sufficient access to credit then the previous trade-off is unambiguously resolved in favor of a higher demand for home ownership.

The main content of the previous lemmas is summarized in Table 1 below, where we describe the equilibrium segmentation according to the households tenure and financial position.

Table 1. Endogenous Segmentation

\begin{tabular}{cccc}
\hline \hline & \multicolumn{3}{c}{ Housing Tenure } \\
& Renters & Buyers & Land \\
Financial Position & & $s=0, g=0$ & Lords \\
& $s>0, h>0$ & $h>0$ & $g>0, h>0$ \\
Constrained & $\checkmark$ & $\checkmark$ & $\checkmark$ \\
Unconstrained & $\varnothing$ & $\varnothing$ & $\checkmark$ \\
\hline
\end{tabular}

In the rest of the paper we focus on stationary steady state equilibria, where all quantities and prices are constant across periods. Given the key result contained in lemma 1 we introduce the following definition.

Definition 3 A Low Valuation Steady State Equilibrium -LVE- (High Valuation Steady State Equilibrium -HVE-) is a set of time invariant allocations $\left\{c^{y}, c^{m}, c^{o}, a^{y}, a^{m}, b, h, s, g\right\}$, prices 
and interest rate $\{p, q, r\}$, and taxes $\{\tau\}$ satisfying the requirements listed in definition 1 and such that all landlords are unconstrained (constrained).

\section{$3 \quad$ Housing and rental markets across steady states}

In this section we investigate the behavior of the main variables of the model across the two types of stationary equilibria just defined, while in the next section we analyze the functioning of the credit market in each of these equilibria and the underlying funding mechanism that sustain their existence. We postpone to section 5 the formal analysis of the conditions of existence and coexistence of both equilibria and how these conditions are shaped by the values of the downpayment parameter, $\theta$, and the tax distortion, $\tau$.

Henceforth, we will mainly deal with aggregate demand functions. These can be readily obtained from their individual counterparts which are contained in the appendix.

Housing market The housing market clearing condition, after imposing equilibrium in the rental market (i.e. $G=S$ ), can be written as

$$
H^{s}=\frac{\gamma \beta}{p}\left\{\begin{array}{c}
\underbrace{\int_{0}^{z_{1}}(1+\beta) \frac{1}{\theta(z)-\frac{1}{\eta}} z d F(z)}_{H R}+\underbrace{\int_{z_{1}}^{z_{2}}(2+\beta) \frac{1}{\theta(z)} z d F(z)}_{H^{B}} \\
+\underbrace{\int_{z_{2}}^{Z} \frac{\eta}{1-\tau} z d F(z)}_{H^{L}}+\underbrace{\int_{0}^{z_{1}} \frac{\theta \eta-(2+\beta)}{\theta(z)-\frac{1}{\eta}} z d F(z)}_{G(=S)}
\end{array}\right\}
$$

where $H^{s}$ denotes the supply of houses and $H^{R}, H^{B}, H^{L}$ and $G$ stand, respectively, for the total expenditure (scaled by the constant $\gamma \beta$ ) devoted to housing purchases by the group of renters, buyers, and landlords (owner occupancy, $H^{L}$, and BLS, $G$ ).

We notice that the above equilibrium condition is invariant across the different types of equilibria considered here, LVE and HVE. The reasons are twofold. First, along the extensive margin (i.e. the limits of integration in (23)), by lemma 3, the threshold values in (21) and (22) remain unchanged across equilibria. Second, along the intensive margin (i.e. the integrands), the individual demand functions of renters (both $h$ and $s$ ) and (constrained) buyers are the same across a LVE and HVE, since their distinctive feature, i.e. the financial position of landlords, is irrelevant for these two groups. Interestingly, the landlords' individual demand for housing services does not depend upon their financial position either:

$$
h_{t+1}=\gamma \beta \frac{1}{(1-\tau) q_{t}} z
$$

To understand why this function is independent of the current and future housing prices, and of the financial status of the landlord (constrained or not), notice that this household optimally equalizes the marginal gain obtained from occupying a house to the benefit of renting it out. 
But for such a purely intratemporal decision the household's financial position and the expected capital gain are both irrelevant, as can be readily seen by combining the first order conditions (12) and (13).

For now, we find particularly helpful to follow a sort of partial equilibrium analysis and interpret the equilibrium condition (23) simply as an equation that can be solved for the market clearing price, $p$, given a particular relative price, $\eta$. Then, we learn that such an equation satisfies $^{14}$

$$
\frac{\partial p}{\partial \eta}=\frac{\gamma \beta}{H^{s}}\left[\int_{0}^{z_{1}} z d F(z)+\frac{1}{1-\tau} \int_{z_{2}}^{Z} z d F(z)\right]>0
$$

There are several features of this derivative worth noting. First, irrespectively of the endowment distribution, changes in $\eta$ do not affect total expenditure on housing services along the extensive margins. ${ }^{15}$ Second, changes in $\eta$ do not matter for the expenditure of buyers, since according to lemma 3, these households do not participate in the rental market. Hence, the effects of changes in $\eta$ on the market clearing price just hinge on the movements along the intensive margin of renters and landlords expenditure, which, at the aggregate level, correspond to the two terms in the right hand side of (24). We deal in detail with the first term, i.e. the response of renters' total expenditure on housing services to changes in the price-to-rent ratio, in the following lemma.

Lemma 4 (Renting-ownership substitution effect). Total expenditure on housing services by renters, $h+s$, is an increasing function of $\eta$.

Proof. As shown in the Appendix the total amount of housing services (measured in consumption units) demanded by a renter can be written as follows, $p(h+s)=\gamma \beta \eta z$. Hence, it trivially follows that $\frac{\partial p(h+s)}{\partial \eta}=\gamma \beta z>0$.

This result is intuitive. For any renter, an increase in $\eta$ leads to two opposite effects. On the one hand, it generates a reduction in the volume of resources devoted to purchase houses. On the other, it leads to an increase in the amount of renting which more than compensates the previous negative effect. To see this, recall that the only reason for a household to obtain housing services from the rental market is the existence of borrowing limits. Thus, renting allows a constrained household to enjoy a larger amount of housing services than the one that it would optimally consume if ownership were its only available choice. ${ }^{16}$ In this precise sense, renting is more inflationary than ownership.

We now explain the last term in expression (24), corresponding to the effects of $\eta$ on the resources devoted to demand housing services by landlords. For any landlord (either constrained

\footnotetext{
${ }^{14}$ Notice that all the relevant functions are differentiable.

${ }^{15}$ The great merit of assuming that the objective function is continuous (i.e. any individual can be an owner and a renter simultaneously) is that, by the theorem of the maximum, the maximizing choices are also continuous in $z$, as the set of of constraints is also continuous in the choice variables. In practical terms this implies that, when applying the Leibniz rule, the variation along the extensive margins will cancel out. This result will apply in all subsequent calculations, unless otherwise noticed.

${ }^{16}$ Notice that since housing is a durable good, in equilibrium $\eta>1$, i.e. renting one unit of housing services is cheaper than buying it.
} 
or not) a higher $\eta$ makes less attractive the BLS investment relative to owner occupancy, thus leading to higher expenditure on owner-occupied dwellings which ultimately translates into higher prices.

Thus, although for different reasons, a higher price-to-rent ratio will lead both renters and landlords to devote more resources to demand housing services. We now turn to the analysis of the rental market.

Rental market In a LVE the supply of renting is governed by the steady state counterpart of the first order condition (17), i.e.

$$
\eta=(1-\tau) \frac{1+r}{r}
$$

As this condition holds, every landlord is willing to elastically supply any amount of rental services up to the limit dictated by its borrowing constraint. That is to say, in a LVE the amount of services traded in the rental market is driven by demand up to the limit of the pool of landlords' credit capacity. By lemma 3 we know that for a sufficiently high value of $\eta$, the demand for renting will be relatively high while the supply will be low (both the number of renters and each individual demand will be high while the number of unconstrained landlords will be low and their margin to supply houses for rent without reaching their borrowing limits narrower). Intuitively, for a sufficiently high value of $\eta$, the ability of the pool of landlords to meet the demand without being borrowing restricted vanishes. Thus, there will be a limiting case that would correspond to what we have defined as a HVE, i.e. every landlord will be constrained and, as a result, the supply of houses for renting will not longer be fully elastic. Formally, in such an equilibrium, the following inequality that specializes (18) in lemma 1 holds

$$
\eta<\frac{1+r}{r}(1-\tau)
$$

From the previous expressions (25) and (26), it can be seen that the interaction between the relative prices, $\eta$, and the interest rate, $r$, will be crucial to characterize the two equilibria. The following lemma and its corollaries formalize this claim.

Lemma 5 If there exists a LVE, then the price-to-rent ratio is bounded above by a certain threshold, $\eta^{*}$, i.e. $\eta^{L V E} \leq \eta^{*}$. If there exists a HVE, then $\eta^{H V E}=\eta^{*}$.

Proof. Let $g^{\max }$ be the amount of renting services supplied by a single landlord, such that it is just at its borrowing limit, i.e. $b=(1-\theta) p\left(h+g^{\max }\right), a^{y}=0$, and the multiplier satisfies $\mu=0$. Thus, $g^{\max }=\frac{\gamma \beta}{p}\left[\frac{2+\beta-\frac{\eta}{1-\tau} \theta(z)}{\theta(z)-\frac{1-\tau}{\eta}}\right] z$, where we have used (25). At the aggregate level, the highest supply of renting, $G^{\max }$, can then be written as

$$
G^{\max }=\frac{\gamma \beta}{p} \int_{z_{2}}^{Z} \frac{2+\beta-\frac{\eta}{1-\tau} \theta(z)}{\theta(z)-\frac{1-\tau}{\eta}} z d F(z)
$$




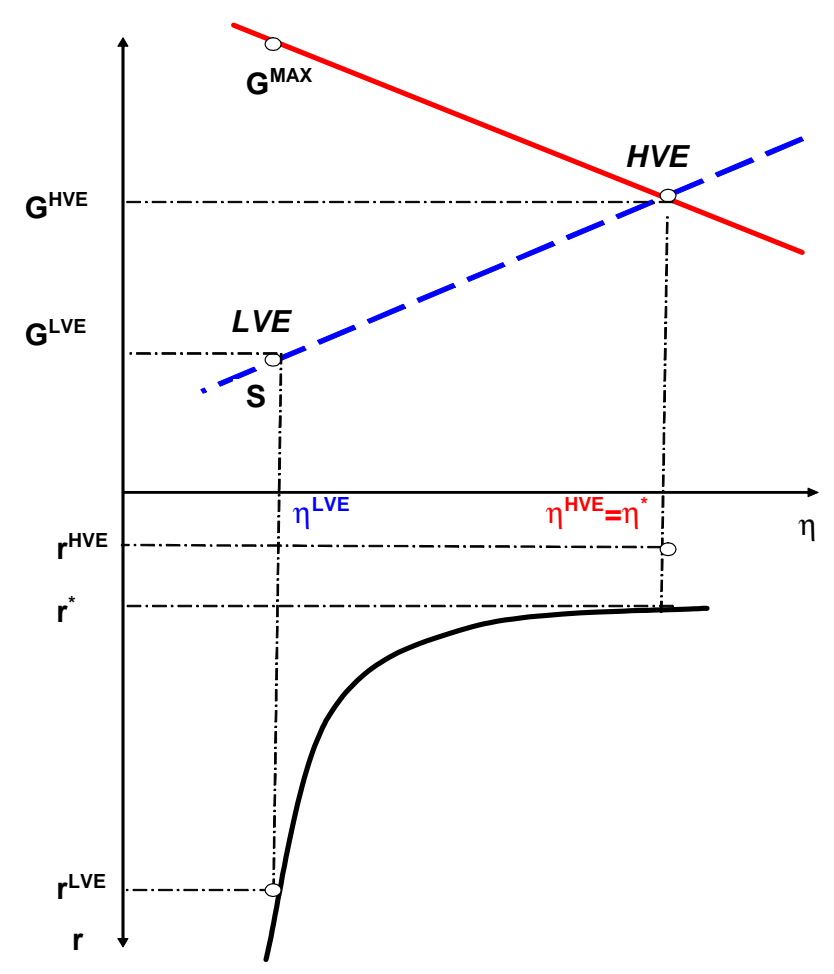

Figure 1: Equilibria in the Rental Market

Using the individual demand functions, the aggregate demand for renting, $S$, is

$$
S=\frac{\gamma \beta}{p} \int_{0}^{z_{1}} \frac{\eta \theta(z)-(2+\beta)}{\theta(z)-\frac{1}{\eta}} z d F(z)
$$

From (24), (27), and (28) it follows that: $\frac{\partial\left[G^{\max }-S\right]}{\partial \eta}<0$ (since $\frac{\partial G^{\max }}{\partial \eta}<0$ and $\frac{\partial S}{\partial \eta}>0$ ). In computing these partial derivatives we note that both the extensive and the intensive margins move in the same direction, i.e. an increase in $\eta$ raises (lowers) both the measure of renters (landlords) and their individual demand (maximum supply, $g^{\max }$ ) for renting. From definition 3 , it follows that two necessary conditions for the existence of a LVE are (25) and $G^{\max }-S \geq 0$. Given that the excess capacity, $G^{\max }-S$, is a decreasing function of $\eta$, then there exists a threshold value $\eta^{*}$, such that $\eta^{L V E} \leq \eta^{*}$.

In the HVE all landlords are constrained. Therefore, a necessary condition for the existence of a HVE is that the excess capacity is equal to zero, i.e. $G^{\max }=G^{H V E}=S^{H V E}$. That is, in equilibrium, $G$ corresponds to the limit above described. Thus, $\eta^{H V E}=\eta^{*}$. This proves the lemma.

We notice that this lemma allows, in the limit of the range of existence of a LVE, for a common relative price across both types of stationary equilibria, namely, $\eta^{*}$. As discussed later in detail in proposition 2, the limit case with $\eta^{L V E}=\eta^{*}$ and $G^{L V E}=G^{\max }$ is not meaningful for comparing the two types of equilibria discussed here, as for the specific parameter configuration that deliver $\eta^{L V E}=\eta^{*}$, this is the only possible equilibrium. Thus, unless otherwise noted, in the remaining of this section we omit this limit case. 
We next state three interesting corollaries that follow directly from lemma 5.

Corollary 1 In a HVE the volume of BLS investment is larger than in a LVE, i.e. $G^{L V E}<$ $G^{\max }$

Corollary 2 If there exists a LVE, then the interest rate, $r^{L V E}$, is bounded below by a certain threshold, $r^{*}$, i.e. $r^{L V E} \geq r^{*}$. Symmetrically, if there exists a HVE then the equilibrium interest rate, $r^{H V E}$, satisfies $r^{H V E}<r^{*}$.

Figure 1 depicts the two alternative equilibria in the rental market just described. In the top panel, the price-to-rent ratio in the HVE, $\eta^{*}$, is determined at the intersection of the $G^{\text {max }}$ and $S$ schedules. The solid line in the bottom panel corresponds to the non-arbitrage condition (25). ${ }^{17}$ Consistently with the necessary condition for a HVE in (26), the equilibrium interest rate, $r^{H V E}$, falls below $r^{*}$. In fact, the HVE price-to-rent ratio, $\eta^{*}$, is determined with no reference to the interest rate (see (27) and (28)). The reason is straightforward: as every household is constrained at the time of buying a house, the interest rate is already sufficiently low so that neither $G^{H V E}$ nor $S$ react to further changes in it. On the contrary, in the LVE, $\eta^{L V E}$ and $r^{L V E}$ simultaneously satisfy (25) (bottom panel) and $\eta^{L V E}<\eta^{*}$ and $G^{L V E}=S^{L V E}<G^{\text {max }}$ (top panel).

Corollary 3 If both equilibria coexist then: (i) $p^{H V E}>p^{L V E}$, and (ii) $q^{H V E}<q^{L V E}$.

Proof. (i) This trivially follows from lemma 5 and (24)

(ii) Using the definition of $\eta$ and the market clearing condition (23), we can write

$$
q=\frac{\gamma \beta}{H^{s}}\left[\int_{0}^{z_{1}} z d F(z)+\frac{2+\beta}{\eta} \int_{z_{1}}^{z_{2}} \frac{1}{\theta(z)} z d F(z)+\frac{1}{1-\tau} \int_{z_{2}}^{Z} z d F(z)\right]
$$

Thus,

$$
\frac{\partial q}{\partial \eta}=-\frac{\gamma \beta}{H^{s}}\left[\frac{2+\beta}{\eta^{2}} \int_{z_{1}}^{z_{2}} \frac{1}{\theta(z)} z d F(z)\right]<0
$$

The above inequality and lemma 5 prove (ii).

The intuition behind the first result has already been discussed (see (24)). We now focus on the second result of this corollary. The inequality in expression (30) crucially hinges on the existence of a group of households that do not participate in the rental market. To see this, we notice that from (24) and (30), it follows that $\frac{\partial p}{\partial \eta} \frac{\eta}{p}<1$. This is very intuitive. Imagine that the interest rate, while higher that $r^{*}$, falls. As described before, the new equilibrium in the rental market calls for higher $\eta$ and, hence, for a larger expenditure on housing services by renters and landlords, which drives $p$ up. However, households with $z \in\left(z_{1}, z_{2}\right)$ do not react to such a fall in $r$ as they are already at their borrowing limit which, in turn, dampens the expansionary

\footnotetext{
${ }^{17}$ In the figures used in this paper we follow this convention: unless the sign of the second derivative of a function in the relevant space is evident we represent that function as a straight line.
} 
effects from lower $r$ in the housing market. If the measure of this latter group is small (large) we would observe that a large part of the adjustment in the rental market takes place through an increase in prices (reduction in rents).

We close this section with a proposition that summarizes the main differences across the two steady state equilibria.

Proposition 1 If both types of equilibrium coexist, then in the LVE (relative to the HVE) (i) housing prices are lower and rents are higher, thus the ratio of housing prices to rents is lower; (ii) the interest rate is higher; and, (iii) the volume of BLS investment is lower.

\section{The long-run funding mechanism}

In this section, we turn our attention to the characterization of the credit market across equilibria.

The demand for funding The aggregate demand for funding has three components corresponding to the groups of renters $\left(B^{R}\right)$, buyers $\left(B^{B}\right)$, and landlords $\left(B^{L}\right)$, where the latter has two terms: debt financing (i) owner occupancy and (ii) BLS investment. After imposing equilibrium in the rental market, the aggregate demand for funds in a LVE can be written as a function of the price-to-rent ratio: ${ }^{18}$

$$
B^{L V E}=\gamma \beta\left\{\begin{array}{c}
\underbrace{\int_{0}^{z_{1}}(1+\beta) \frac{1-\theta(z)}{\theta(z)-\frac{1}{\eta}} z d F(z)}_{B^{R}}+\underbrace{\int_{z_{1}}^{z_{2}}(2+\beta) \frac{1-\theta(z)}{\theta(z)} z d F(z)}_{B^{B}}+ \\
\underbrace{\int_{0}^{z_{1}}\left(1-\frac{1-\tau}{\eta}\right) \frac{\eta \theta(z)-(2+\beta)}{\theta(z)-\frac{1}{\eta}} z d F(z)+\int_{z_{2}}^{Z}\left(\frac{\eta}{1-\tau}-(2+\beta)\right) z d F(z)}_{B^{L}}
\end{array}\right\}
$$

After some algebra it can be shown that $B^{L V E}$ is an increasing function of $\eta$ :

$$
\frac{\partial B^{L V E}}{\partial \eta}=\gamma \beta\left\{\int_{0}^{z_{1}}\left[1+(1+\beta) \frac{\tau \theta(z)}{(\eta \theta(z)-1)^{2}}\right] z d F(z)+\int_{z_{2}}^{Z} \frac{1}{1-\tau} z d F(z)\right\}>0
$$

Much as in the case of the aggregate expenditure on housing services, the positive effects of $\eta$ on the demand for debt hinge on the movements along the intensive margin of renters and landlords. The intuition for this net positive effect is reminiscent from the one arising in the discussion of the housing market in the previous section, i.e. an increase in $\eta$ raises the overall

\footnotetext{
${ }^{18}$ Notice that, given that in a LVE the landlords' supply of houses for renting is completely elastic and the interest rate paid on deposits and debt is the same, we can not compute $a^{y}$ and $b$ separately, but only the aggregate net position for the whole group of landlords. For the ease of the exposition, we follow the convention of treating the (negative of) aggregate net financial position of landlords as debt.
} 
demand for housing services, thus increasing the demand for funding. As before, the positive total effect embedded in the first term in the right side of (32) comes from a negative effect on the demand for funding by renters that is more than compensated by the increase in the demand by landlords necessary to finance a higher volume of houses for renting. The second (positive) term is the consequence of the increased demand for housing services by landlords. Further, according to (25) and (32), it follows that $\frac{\partial B^{L V E}}{\partial r}<0$.

Lemma 6 If both types of equilibria coexist then in a LVE (relative to a HVE) the total volume of lending is lower.

Proof. As in the previous LVE case, imposing equilibrium in the rental market allows us to obtain the following expression for aggregate demand for funds in the $\mathrm{HVE}^{19}$

$$
B^{H V E}=\gamma \beta\left\{\begin{array}{c}
\underbrace{\int_{0}^{z_{1}}(1+\beta) \frac{1-\theta(z)}{\theta(z)-\frac{1}{\eta}} z d F(z)}_{B^{R}}+\underbrace{\int_{z_{1}}^{z_{2}}(2+\beta) \frac{1-\theta(z)}{\theta(z)} z d F(z)}_{B^{B}}+ \\
\underbrace{\int_{0}^{z_{1}} \frac{\eta \theta(z)-(2+\beta)}{\theta(z)-\frac{1}{\eta}} z d F(z)+\int_{z_{2}}^{Z}\left(\frac{\eta}{1-\tau}-\frac{(1+\beta) \theta(z)}{\left.\theta(z)-\frac{1-\tau}{\eta}\right) z d F(z)}\right.}_{B^{L}}
\end{array}\right\}
$$

From (32) and lemma 5, it follows that $\lim _{\eta} \nearrow \eta^{*} B^{L V E}=B^{H V E}\left(\eta^{*}\right)$, i.e. $B^{L V E}<B^{H V E}\left(\eta^{*}\right)$ $\Leftrightarrow \eta^{L V E}<\eta^{*}$.

Finally, notice that now $\frac{\partial B^{H V E}}{\partial \eta}>0$, as well (for the same reasons described before), but in contrast to the LVE, given that every household is constrained we trivially get $\frac{\partial B^{H V E}}{\partial r}=0$.

The supply of funds We have shown in lemma 5 and its corollaries that a HVE is only consistent with a relatively low level of interest. We now investigate the mechanism that allows the economy to generate a sufficient supply of funding so as to sustain a high volume of lending and low interest rates. The following lemma describes the supply of funds across the different groups of households.

Lemma 7 (Savings and interest rates). The slope of each group's saving function (i.e. accumulation of deposits) satisfies: (i) $\frac{\partial a^{R}}{\partial r}>(<) 0$ in a LVE (HVE), (ii) $\frac{\partial a^{B}}{\partial r}<0$, irrespective of the type of equilibria, and (iii) $\frac{\partial a^{L}}{\partial r}>(<) 0$ in a $L V E(H V E)$; where $a^{k}$, for $k=R, B, L$, stands for the purchases of deposits by renters, buyers and landlords, respectively.

\footnotetext{
${ }^{19}$ Contrary to the case of the demand for housing services, the aggregate demand for funds is not isomorphic across equilibria due to the term corresponding to the landlords.
} 
Proof. Using the individual demands described in the appendix it can be shown that for any constrained household the form of the saving function (up to a constant, $\gamma \beta^{2}$ ) is:

$$
a^{k}= \begin{cases}\frac{1-(1+r)(1-\theta(z))}{\theta(z)-\frac{1}{\eta}} & \text { if } k=R \\ \frac{2+\beta}{1+\beta} \frac{1-(1+r)(1-\theta(z))}{\theta(z)} & \text { if } k=B \\ \frac{1-(1+r)(1-\theta(z))}{\theta(z)-\frac{(1-\tau)}{\eta}} & \text { if } k=L\end{cases}
$$

We now show that the way a change in $r$ affects $a^{k}$ depends crucially on the type of equilibrium considered.

First, in a HVE the value of $\eta$ that clears the rental market does not vary with the interest rate. Hence, from (34), we learn that

$$
\left.\frac{\partial a^{k}}{\partial r}\right|_{r<r^{*}}<0, \quad k=R, B, L
$$

Second, for a sufficiently high interest rate (i.e. $r>r^{*}$ ), the relevant rental market equilibrium condition is (25), and a new channel of influence of $r$ on $a^{k}$ arises, as (25) makes clear that changes in $r$ move $\eta$ in the opposite direction. We now consider how this extra channel operates across the three groups:

1. For a renter, some simple algebra shows that $\left.\frac{\partial a^{R}}{\partial r}\right|_{r>r^{*}}>0$ iff

$$
\frac{1-(1+r)(1-\theta(z))}{\left(\theta(z)-\frac{1}{\eta}\right)(1+r)}>(1-\theta(z))(1-\tau)(1+r),
$$

where it can be shown that this inequality necessarily holds. To see this, we notice that the following inequality also holds: $\frac{1-(1+r)(1-\theta(z))}{\left(\theta(z)-\frac{1}{\eta}\right)}>1+r$, i.e. from the first order conditions, it follows that the intertemporal rate of substitution of a renter has to be greater than the (gross) interest rate. Hence, a sufficient condition for $(36)$ is $\theta(z)>1-\frac{1}{(1-\tau)(1+r)}$. But, according to (25) and lemma $3, \theta(z)>(2+\beta) \frac{r}{(1-\tau)(1+r)}$. Then, it trivially follows that $(2+\beta) \frac{r}{(1-\tau)(1+r)}>$ $1-\frac{1}{(1-\tau)(1+r)}$ holds over the relevant range of $r$ and $\tau$ (i.e. both positive). Thus, $\left.\frac{\partial a^{R}}{\partial r}\right|_{r>r^{*}}>0$.

2. For a buyer, however, the feedback from $r$ to $\eta$, does not affect any of its relevant decisions, including how to allocate consumption between the first and second period of its life, so $\frac{\partial a^{B}}{\partial r}<0$ still holds for $r>r^{*}$.

3. Finally, for an unconstrained landlord, whose intertemporal rate of substitution is simply $1+r$, it follows that $\left.\frac{\partial a^{L}}{\partial r}\right|_{r>r^{*}}>0$.

This lemma contains the result that lies at the core of the funding mechanism that allows for multiple steady state equilibria, namely the reversal of the slope of the supply of funds function for two groups of households (renters and landlords) around a HVE. To understand this mechanism, it is helpful to decompose the effects of changes in $r$ on the amount of resources required to repay outstanding mortgages and hence on each household's networth at the time of accumulating loanable funds. First, changes in $r$ directly affect the amount of interest charges; 
and second, they also influence the desired amount of debt. The latter effect does not operate in a HVE since households find optimal to exhaust their borrowing capacity, thus making the aggregate demand for debt independent of the interest rate. Hence, the only effect from further reductions in the interest rate is to raise every household's networth, thus inducing higher saving rates.

Around a LVE the effects of changes in the interest rate matter for the household's networth through both effects, i.e. interest payments and desired amount of debt. In particular, as shown before, the total amount of debt held by renters and landlords (i.e. $B^{R+L} \equiv B^{R}+B^{L}$, in expression (31)) decreases with the interest rate. Moreover, the amount of resources devoted to repay outstanding mortgages, i.e. $(1+r) B^{R+L}(r)$, is a decreasing function of the interest rate. The reason behind this result parallels the one given in the previous analysis of the housing market: a reduction in the interest rate induces, given (25), an increase in the relative price $\eta$, which translates into a higher demand for debt due to a larger equilibrium volume of BLS investment and a higher demand for housing services by landlords.

\section{Existence and coexistence}

\subsection{Small tax distortions}

The purpose of this section is to investigate the conditions for the existence and coexistence of both types of equilibria. We also study how changes in the fundamentals of most interest (tax and downpayment) affect the range of coexistence. We will proceed sequentially by first concentrating on a low tax distortion set up, i.e. $\tau \searrow 0$. This limiting case will simplify the analysis since the fraction of constrained buyers shrinks, thus allowing us to focus only on the interaction between renters and landlords which, in turn, makes the analysis independent of the endowment distribution.

\section{Proposition 2 (Existence and coexistence of equilibria for $\tau \searrow 0$ )}

a) Existence. (i) There exists a unique $L V E$ if $\theta \leq \bar{\theta}$. (ii) There exits a unique $H V E$ if $\underline{\theta} \leq \theta<\bar{\theta}$.

b) Coexistence. There exist a non-empty set of $\theta$ 's for which both equilibria co-exist, i.e. $\bar{\theta}>\underline{\theta}$.

Proof. The complete proof is in the Appendix.

We now outline the main intuition behind these results. Let us first focus on the LVE. In this case, irrespectively of distributional issues, uniqueness is warranted since as $\tau \searrow 0$ the measure of constrained buyers becomes negligible (see lemma 3), so making the aggregate excess demand for credit a monotonically decreasing function of the interest rate. Thus, if a LVE exists, equilibrium $r$ is unique and so are the rest of prices and quantities. But existence of a LVE will require a not too high value of $\theta$ since as noticed in the proof of lemma 5 , a necessary condition for the existence of a LVE is a non-negative excess capacity in the rental market, i.e. $G^{\max }-S \geq 0$. Since $\frac{\partial G^{\max }}{\partial \theta}<0, \frac{\partial S}{\partial \theta}>0$, i.e. higher downpayment reduces the 

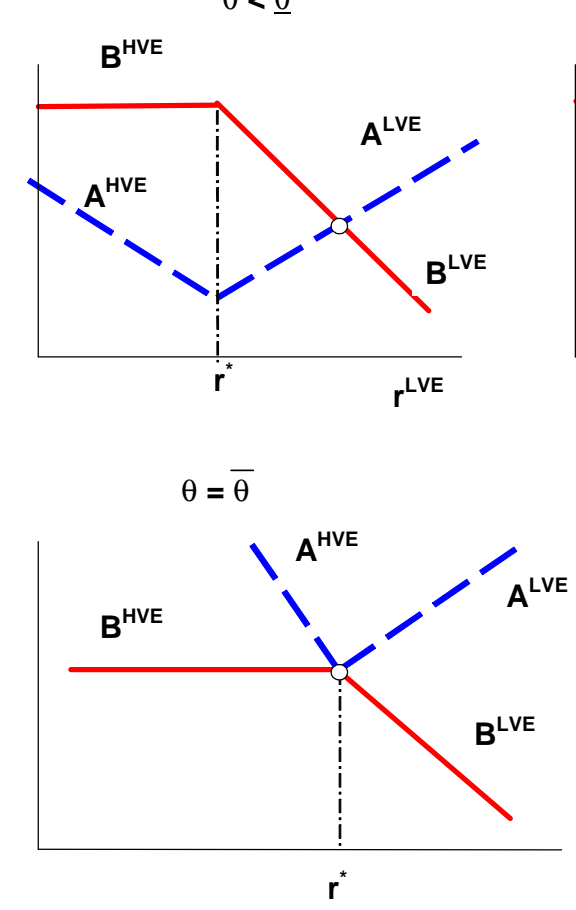

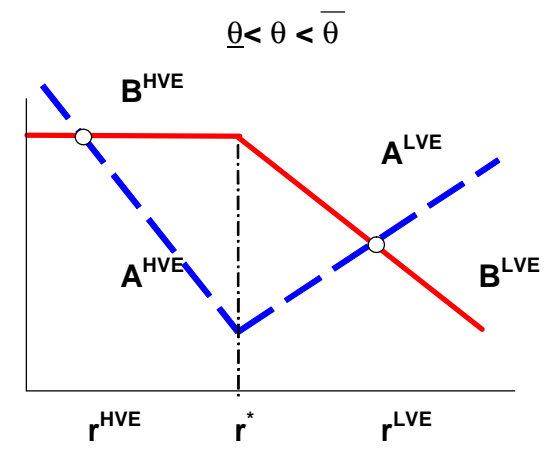

$\theta>\bar{\theta}$

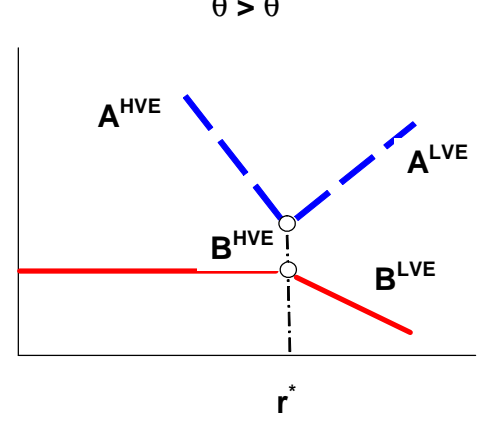

Figure 2: Equilibria in the Credit Market

ability of (unconstrained) landlords to supply houses in the rental market while it increases the demand for rental services, we learn that $\frac{\partial\left[G^{\max }-S\right]}{\partial \theta}<0$. Hence, there exists a unique $\theta$, call it $\bar{\theta}$, such that $G^{\text {max }}-S=0$ with (25) still holding. Clearly, if $\theta>\bar{\theta}$ then these two necessary conditions can not hold simultaneously.

We turn now into the analysis of the HVE. Uniqueness here follows from the monotonicity of the aggregate excess demand for credit too, which now is increasing in the interest rate as above noted. Further, this function is negatively related to $\theta$, so that $\frac{d r}{d \theta}>0$. Hence there exists a a lower bound $\underline{\theta}$, such that for $\theta<\underline{\theta}$ the excess demand of credit is strictly positive even as $r$ approaches its lower bound, i.e. zero. Finally, if $\theta>\bar{\theta}$, then there is no $\eta$ such that both rental and credit markets clear, and $\eta<\frac{1+r}{r}(1-\tau)$, simultaneously. Much as low values of $\theta$ prevent the credit market from clearing at $r=0$ when at the same time the rental market clears, a sufficiently high $\theta$ precludes the credit market from clearing at the highest possible rate, i.e. $r \nearrow r^{*}$.

In sum, both steady state equilibria will coexist whenever the borrowing limit takes intermediate values. On the one end, $\theta$ can not be high enough so that it creates a positive excess supply of credit for any admissible interest rate. On the other, very low values of $\theta$ may imply that the whole economy can not generate enough savings to sustain an equilibrium in which every household exhausts its collateral constraint, i.e. a HVE.

The four panels of Figure 2 correspond to the alternative scenarios implicit in the preceding discussion. The top-left panel depicts a situation in which the borrowing limit is too loose to sustain a HVE (i.e. $\theta<\underline{\theta}$ ), thus, even as $r$ approaches zero there persists a positive excess 


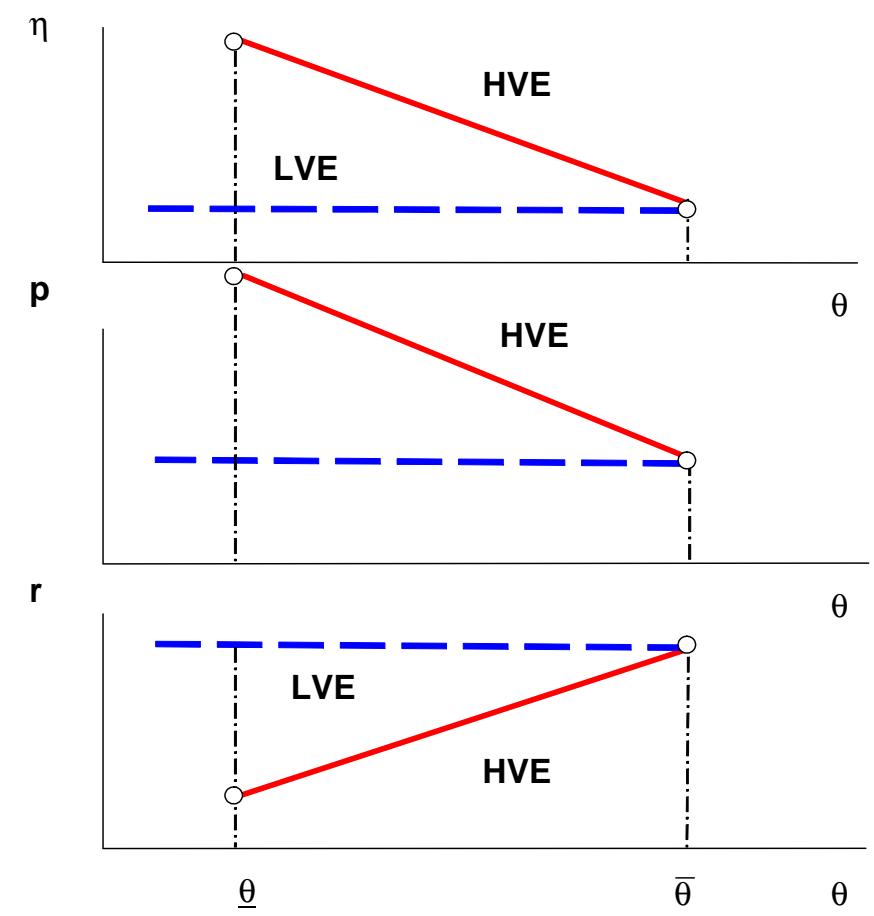

Figure 3: Equilibria coexistence for intemediate values of theta.

demand for credit. The top-right panel is consistent with a value for the downpayment lying inside the coexistence range, i.e $\underline{\theta}<\theta<\bar{\theta}$, where the demand and supply of funds cross twice. The bottom-left panel displays the corner case corresponding to $\theta=\bar{\theta}$, for which there exists a unique possible steady state equilibrium, i.e. the limiting case with $r=r^{*}$. Finally, the bottom-right panel displays a case with $\theta>\bar{\theta}$, and hence the excess demand for credit is always strictly negative regardless of the value of the interest rate and, as a result, for sufficiently high $\theta$ there is not any interior steady state equilibrium.

Corollary 4 Within the range of coexistence the distance, as measured by the differences in the price-to-rent ratio, the housing price, and the interest rate, across both equilibria is decreasing in the size of the downpayment, $\theta$.

This is an intuitive result in which we essentially emphasize that the size of the multiplier of $\theta$ on the relevant prices mentioned in the corollary is higher in the HVE than in the LVE inside the range of coexistence. In the HVE changes in $\theta$ will affect every household within the same cohort, while in the LVE there is always a fraction of households that are not financially constrained (landlords) so their optimal behavior is not affected by marginal changes in the downpayment requirement. In other words, in the HVE the extra capacity of the whole economy to "produce" collateral following a fall in $\theta$ is fully exploited while only a fraction of it (that corresponding to renters and buyers) is actually used in the LVE.

Figure 3 describes how the equilibrium housing price, the price-to-rent ratio, and the interest rate depend upon $\theta$ across steady states. Notice that the HVE schedule always lies above the 
LVE one for $p$ and $\eta$, while it is below for $r$. First, from expression (30) it follows that, by making negligible the measure of households that do not participate in the rental market, changes in $\eta$ fully translate into changes in $p$, thus leaving $q$ unchanged. Second, in the LVE, a negligible measure of constrained buyers implies a zero slope for the aggregate excess demand of credit, i.e. $\frac{\partial A}{\partial \theta}=\frac{\partial B}{\partial \theta}=0$. On the one hand, the slope of the aggregate saving is independent of $\theta$, since by making $\tau \searrow 0$, the intertemporal rate of substitution of renters becomes close to $1+r$, i.e. independent on the size of the downpayment. On the other, changes in $\theta$ induce opposite movements in the debt of renters and landlords. This result follows from both lemma 4 and the fact that $q$ remains unchanged across equilibria. Hence, an increase in the size of the downpayment will leave unchanged the aggregate amount of debt, since the reduction pursued by renters (due to the substitution out of the housing market) will be exactly compensated by an increase in the debt devoted to finance the rise in BLS investment. This in turn isolates the equilibrium interest rate from changes in the downpayment, i.e. the multiplier in the LVE is $\frac{d r}{d \theta}=0 .{ }^{20}$ From (25), it also follows that $\frac{d \eta}{d \theta}=0$. The horizontal lines representing the LVE in Figure 3 capture these results.

Contrary to the case of the LVE, the multiplier of $\theta$ is not zero in the HVE. As explained before, a higher downpayment reduces the ability of landlords to supply houses in the rental market, while increases the demand for renting, which taken together imply that $\frac{d \eta}{d \theta}<0$. Moreover, using expression (24), it follows that $\frac{d p}{d \theta}<0$, that is, in the HVE easier access to credit will result in higher housing prices. These results are intuitive. As the financial constraint relaxes, since every single household is at its borrowing limit when buying a house, the total amount of lending increases, thus expanding the overall demand for dwellings, which in turn pushes prices up. Further, softer collateral constraints tend to rise the excess demand for credit and, hence, $\frac{d r}{d \theta}>0$.

The above mutual feedback between housing prices and available collateral has been exploited by Stein (1995) to show that under some conditions this mechanism may give raise to multiple equilibrium housing prices. In the model of this paper, while the collateral channel is active as an amplifying mechanism, it is not sufficient to deliver multiple equilibria. Here we rather stress that for this channel to work at its highest force the interest rate must be sufficiently low to provide households with the right incentives to borrow up to the limit of their available collateral, which here happens at a HVE.

\subsection{The case of large tax distortions}

While the assumption of a small tax rate makes simple the analysis of the conditions under which both equilibria may coexist, as no critical piece hinges on the particular income distribution function at work, it comes at some costs. On one end, the multiplier effects of the downpayment parameter, $\theta$, on prices and interest rates in a LVE become negligible, so we lose insight into

\footnotetext{
${ }^{20}$ An alternative way of understanding the reasons for a zero $\theta$-multiplier around a LVE can be provided after noticing that the overall demand for housing services by a landlord and a renter, respectively, only depend on the value of rents (see the appendix). Thus, as rents remain unchanged so it does the overall demand for housing services and, as a consequence of this, the excess demand for credit.
} 
an interesting dimension of the model, namely, the way interest rates and prices respond to e.g. the easing of the borrowing limits. On the other, one may be naturally interested on how changes in taxation determine the coexistence of the two types of steady states since, as noted before, $\tau$ beyond representing the particular size of the tax distortion in the rental market, here it captures the only source of bias towards ownership versus renting. This section fills these gaps by, first, analyzing the impact of changes in $\theta$ on some of the most relevant endogenous variables in a LVE; and second, by describing an important implication for the conditions for equilibria coexistence arising from a "tax experiment" consisting in a permanent increase in $\tau$.

\subsubsection{Downpayment changes in a LVE}

As $\tau$ becomes non-negligible, according to lemma 3, in any interior steady state there will be a non-zero measure of constrained buyers. This implies that changes in $\theta$ may now shift both the aggregate saving and debt schedules in a non-negligible measure. Yet, the direction of these shifts is not unambiguous. To see that the movement in the aggregate debt schedule may go in either direction, it is convenient to rewrite (31) as

$$
B^{L V E}=\gamma \beta\left\{\begin{array}{c}
\int_{0}^{z_{1}}\left[(\eta-1+\tau)-(1+\beta)\left(1+\frac{\tau}{\eta \theta-1}\right)\right] z d F(z)+ \\
\int_{z_{1}}^{z_{2}}(2+\beta) \frac{1-\theta}{\theta} z d F(z)-\int_{z_{2}}^{Z}\left(2+\beta-\frac{\eta}{1-\tau}\right) z d F(z)
\end{array}\right\}
$$

where the first term in the right hand side captures the demand for funding by renters plus the debt required by landlords for BLS investments, and the second and third terms, respectively, represent the debt required by both buyers and landlords to finance purchases for owner occupancy. Interestingly, a reduction in $\theta$ will increase the total debt held by buyers and renters, but it will reduce that of landlords. The intuition behind these opposite effects is simple. On the one hand, lower $\theta$ translates directly into a higher demand for funds by households who were already at their borrowing limits, that is, renters and constrained buyers. On the other, a relaxation of the financial constraint leads renters to demand less renting services (i.e. providing higher incentives towards ownership) which leads to a fall in the volume of debt demanded by landlords. While this latter effect dominates the rise in the debt held by renters, ${ }^{21}$ the overall net effect, due to the presence of the constrained buyers, is necessarily ambiguous. Further, as can be seen from (34), the aggregate saving function will change in a non-trivial way in responses to changes in $\theta$, shifting the supply of funds by renters and constrained buyers in opposite directions. In sum, the aggregate excess demand for credit may shift either up or downwards in responses to changes in the size of the downpayment, with the final outcome depending to a large extent on the value of the tax and the shape of the income distribution. Thus, even if the

\footnotetext{
${ }^{21}$ Formally, this can be seen from the positive sign of the derivative of the first term in the right side of (37). This positive overall effect is reminiscent from the substitution highlighted in lemma 4. In particular, a rise in the size of the downpayment will reduce the demand for debt of renters. Given that those households are constrained, this translates into a reduction in homeownership that is more than compensated by the increase in renting services. This higher demand of renting activities will be meet by landlords by demanding more debt in an amount that compensate the drop in the debt of the renters.
} 
aggregate excess demand function is a decreasing function of the interest rate, ${ }^{22}$ as in the small $\tau$ case, it is clear that when allowing for non-small $\tau$, changes in the size of the downpayment may lead to either positive or negative shifts in the equilibrium interest rates, and hence on relative prices.

In view of these reflections we analyze the $\theta$-multiplier along two different cases, depending on the sign of $\frac{d r}{d \theta}$. Importantly, these two cases may have opposite implications for the multiplier effects of changes in $\theta$ on both housing and rents as stated in the next lemma.

Lemma 8 (Multiplier effects of $\theta$ on housing prices and rents in the LVE) If $\frac{d r}{d \theta}>(<)$ 0 , then the sign of the housing price and rent multipliers is: $\frac{d p}{d \theta}<(\gtrless) 0$ and $\frac{d q}{d \theta} \gtrless(<) 0$.

Proof. The proof follows directly from equilibrium conditions (23) and (29).

The result in the lemma is intuitive. As easier credit leads to a lower equilibrium interest rate, that is the case in which $\frac{d r}{d \theta}>0$, and, according to expression (25), to a higher $\eta$, the net effect on $p$ is unambiguously positive, since the demand for housing services by the three groups of households shifts upwards, yet for different reasons: while the effect of a fall in $\theta$ on the demand of houses by constrained buyers follows directly from the subsequent higher borrowing capacity, the shift in the final joint demand for housing services by renters and landlords is an indirect one, as it operates via relative prices, as discussed in proposition 1. However, the net effect on rents may go either way. On the one hand, a rise in $\eta$ is not fully passed into higher prices, $p$, but, rather, depresses rents (see (30)). On the other, a fall in $\theta$ leads to higher demand for housing services by constrained buyers which, in turn, exerts upward pressure, not only on prices but also on rents (see expression (29)).

On the other hand, a negative impact from a fall in $\theta$ on $r$ is also possible, reflecting the fact that the positive shift in the aggregate demand for funds following looser borrowing limits may not be matched by an equivalent shift in the supply function. In this case, if $\eta$ responds strongly to the fall in $\theta$, a reduction in $p$ is possible, a case that would correspond to a situation in which the positive effect on the demand for housing services by constrained buyers is outweighed by the negative effect on the demand by renters and landlords.

In sum, the sign of the impact from a change in the credit limits on prices and rents, when BLS investments are carried over by unconstrained agents, will ultimately depend not only on the direct effect via higher demand by those households who are at the limit of their borrowing capability, but also on the consequences of such an innovation in the credit market on the equilibrium interest rate and, in turn, on the price-to-rent ratio. We think of this as an interesting general equilibrium result: relaxing collateral constraints may not always result

\footnotetext{
${ }^{22}$ Notice that as described in lemma 7, the supply of credit by the group of buyers is negatively related to the interest rate while the opposite holds for renters and landlords in a LVE. Hence, both the size of the tax distortion and the shape of the income distribution will now determine the sign of the slope of the aggregate saving function and, hence, that of the excess demand function. Thus, the results described in the previous section regarding the slope of the aggregate excess demand for credit will hold, for any arbitrary income distribution, as long as the tax is not too large.
} 


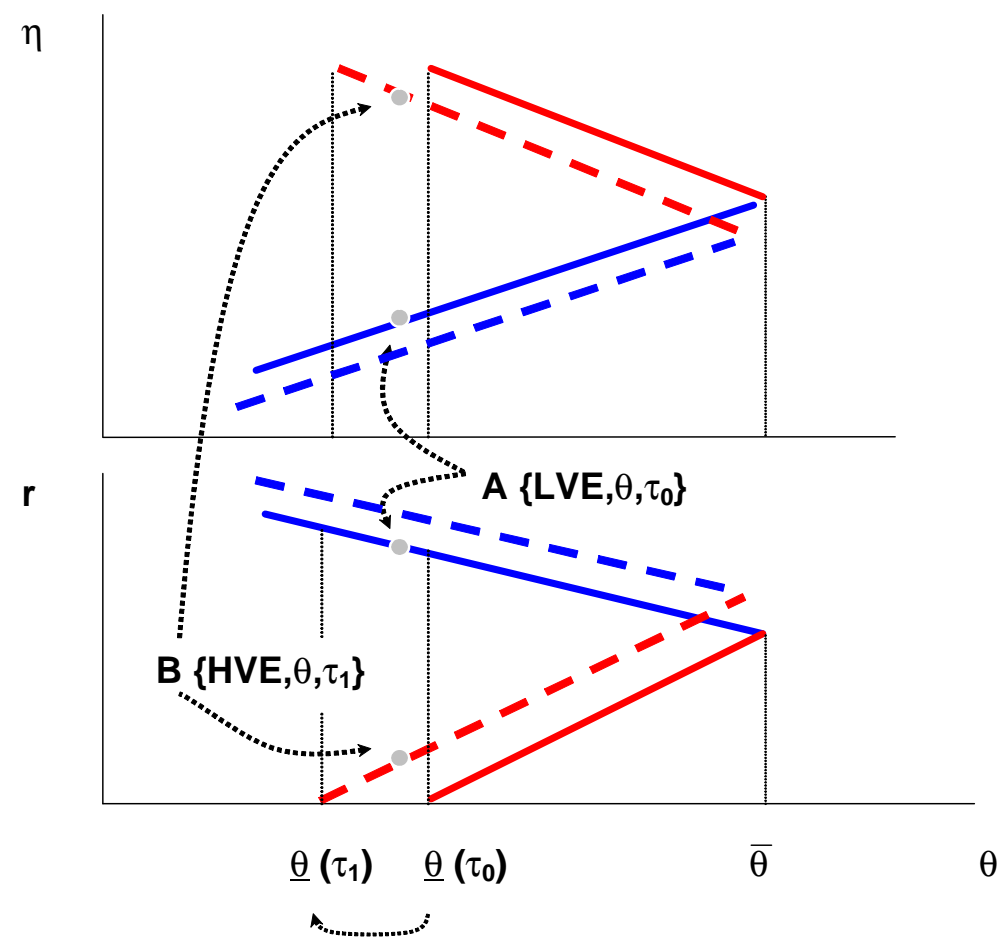

Figure 4: The effects of an increase in the tax rate, $\tau$.

into higher house prices, since easier credit may trigger higher interest rates which ultimately discourage the purchases of houses.

\subsubsection{A tax experiment}

We next ask what are the effects of a rise in $\tau$ in terms of the conditions for the existence of a HVE. In particular, we look at an initial (pre-shock) scenario in which only a LVE is feasible, say because when imposing the HVE pricing conditions the underlying fundamentals are such that the excess demand for credit is strictly positive even as $r$ approaches zero, as described in proposition 2. Then, we show that a rise in the tax rate points towards the direction of making a HVE a feasible outcome. The key formal result is contained in the following lemma.

Lemma 9 (Tax experiment). Under general conditions, $\underline{\theta}$ is decreasing in $\tau$.

Proof. See the Appendix.

Recall that $\underline{\theta}$ is the minimum value for $\theta$ such that, given everything else, a HVE is feasible. Hence according to the previous lemma a rise in $\tau$, by lowering $\underline{\theta}$, may allow for the fulfillment of the necessary conditions for a HVE when those conditions could not be met for a smaller tax. To better understand the way this mechanism operates, notice that a large volume of BLS investment, in equilibrium, goes in hand with high prices and, by the same token, with a high demand for funding (see the discussion of lemma 6). Then, a rise in $\tau$ reduces the incentives 
for that form of investment, thus decreasing the funding requirements to sustain a HVE. Figure 4 depicts this comparative statics analysis. The initial parameter configuration $\left(\tau_{0}, \theta\right)$ is such that $\underline{\theta}\left(\tau_{0}\right)>\theta$, and hence there exists no HVE. Then, a sufficiently large rise in the tax rate, $\tau_{1}>\tau_{0}$, reduces $\underline{\theta}$ below $\theta$, thus allowing for a HVE.

Therefore, this feature of the model can be reconciled with the idea that a positive shock in the home ownership bias may ultimately open the possibility for the emergence of a new steady state equilibrium in which housing prices go up. Yet, here we emphasize that in order to understand the channel through which this mechanism operates it is critical to put the effects of that shock on the credit market in their right place. Moreover, in light of the results contained in proposition 1, such a change favoring ownership may, in the long run, be consistent with a larger measure of households who find it optimal to rent. This seemingly paradoxical equilibrium result reflects the fact that a stronger ownership bias does increase the equilibrium amount of housing services obtained through ownership by only those households with looser credit limits (landlords), while at the same time others (renters) are crowded out from ownership.

\section{Conclusions}

In this paper we have developed a simple general equilibrium OLG model to explain the joint determination of housing prices, rents, and interest rates. Borrowing limits generate a mistmatch between desired and available funds to finance housing purchases. Individual heterogeneity on this mismatch gives rise to three different types of households: renters, buyers, and landlords; where the latter find optimal to invest in houses to let and sell afterwards (BLS investments). As the price-to-rent ratio is less than unity, renting allows those households with a lower borrowing limit to enjoy a larger dwelling than the one that could be obtained through outright ownership. An increase in that ratio (i) rises the equilibrium volume of BLS investment and, hence, of renting, pushing the housing price up; and (ii) leads landlords to increase their own consumption of housing services, reinforcing the inflationary effect on prices. The return of the BLS activity depends on the link between the price-to-rent ratio and the interest rate. We show that such a link varies according to whether landlords find optimal to exhaust their borrowing limits or not.

An important feature of the model is that under some conditions there may exist two different steady state equilibria for a given set of fundamentals. A low valuation equilibrium (LVE) in which only the landlords find optimal not to exhaust their borrowing limits at the time of making their tenure choice decision, and a high valuation equilibrium (HVE) in which every household is financially constrained at the time of purchasing a house. Further, in a LVE (relative to a HVE) housing prices, the price-to-rent ratio, the volume of BLS investment, and the amount of debt are relatively lower, while interest rates and rents are higher. We emphasize that the presence of collateral constraints plays a key role in allowing for the coexistence of these two kinds of steady states. First, a high demand for housing services in a HVE is possible because the resulting higher equilibrium price expands the available collateral in hands of borrowers. Second, we show that low interest rates needed to sustain a HVE are 
possible because of the existence of a positive networth effect that fuels the future availability of funds through a reduction in the cost of servicing outstanding debts of constrained households. Although the model is based on a number of special features, we think of it as a useful first step in developing a more general framework within which one may understand the recurrent episodes of rapid increases in housing markets as rational speculative paths along which the economy may move from a LVE to a HVE.

Our analysis has confined the endogenous funding mechanism to a closed economy. Nevertheless, along the lines suggested by Caballero, Farhi and Hammour (2005), this mechanism could also have an exogenous component, if the economy can have access to external funding. Adding this extra source of funding would tend to enlarge the set of conditions under which both equilibria coexist, as a critical obstacle for a HVE is an insufficient supply of funds. In Arce and López-Salido (2006) we allow for external credit conditions to play a role in the behavior of the housing market; and we explicitly consider a non-competitive banking sector so that de supply of credit depends upon the pass-through from international interest rates to domestic mortgage rates. 


\section{Appendix}

Individual demand functions

Below we provide the explicit solution of the utility maximization problem faced by the households according to the segmentation scheme described in section 2 .

\section{Constrained Renters}

$$
\begin{aligned}
c_{t}^{y} & =\gamma z ; \quad c_{t+1}^{m}=\gamma \beta \frac{\delta_{t+1}}{p_{t}\left(\theta(z)-\frac{1}{\eta_{t}}\right)} z ; \quad c_{t+2}^{o}=\gamma \beta^{2} \frac{\delta_{t+1}\left(1+r_{t+2}\right)}{p_{t}\left(\theta(z)-\frac{1}{\eta_{t}}\right)} z \\
h_{t+1} & =\gamma \beta(1+\beta) \frac{1}{p_{t}\left(\theta(z)-\frac{1}{\eta_{t}}\right)} z ; \quad s_{t+1}=\gamma \beta \frac{\theta(z) \eta_{t}-(2+\beta)}{p_{t}\left(\theta(z)-\frac{1}{\eta_{t}}\right)} z ; \quad g_{t+1}=0 \\
b_{t+1} & =\gamma \beta(1+\beta) \frac{1-\theta(z)}{\theta(z)-\frac{1}{\eta_{t}}} z ; \quad a_{t+1}^{y}=0 ; \quad a_{t+2}^{m}=\gamma \beta^{2} \frac{\delta_{t+1}}{p_{t}\left(\theta(z)-\frac{1}{\eta_{t}}\right)} z
\end{aligned}
$$

where $\delta_{t+1} \equiv p_{t+1}-\left(1+r_{t+1}\right)(1-\theta(z)) p_{t}$.

\section{Constrained Buyers}

$$
\begin{aligned}
c_{t}^{y} & =\gamma z ; \quad c_{t+1}^{m}=\gamma \beta \frac{2+\beta}{1+\beta} \frac{\delta_{t+1}}{\theta(z) p_{t}} z ; \quad c_{t+2}^{o}=\gamma \beta^{2} \frac{2+\beta}{1+\beta} \frac{\delta_{t+1}\left(1+r_{t+2}\right)}{\theta(z) p_{t}} z \\
h_{t+1} & =\gamma \beta(2+\beta) \frac{1}{\theta(z) p_{t}} z ; \quad s_{t+1}=0 ; \quad g_{t+1}=0 \\
b_{t+1} & =\gamma \beta(2+\beta) \frac{1-\theta(z)}{\theta(z)} z ; \quad a_{t+1}^{y}=0 ; \quad a_{t+2}^{m}=\gamma \beta^{2} \frac{2+\beta}{1+\beta} \frac{\delta_{t+1}}{\theta(z) p_{t}} z
\end{aligned}
$$

Unconstrained Landlord The system corresponding to unconstrained landlord is such that $s_{t+1}=0$, and $\varphi_{t+1}^{h}=\varphi_{t+1}^{g}=\varphi_{t+1}^{a}=\varphi_{t+1}^{b}=\mu_{t+1}=0$. Hence, the optimal plan takes the form:

$$
\begin{aligned}
c_{t}^{y} & =\gamma z ; \quad c_{t+1}^{m}=\gamma \beta\left(1+r_{t+1}\right) z ; \quad c_{t+2}^{o}=\gamma \beta^{2}\left(1+r_{t+1}\right)\left(1+r_{t+2}\right) z \\
h_{t+1} & =\gamma \beta \frac{1}{(1-\tau) q_{t}} z ; \quad s_{t+1}=0 ; \quad g_{t+1} \text { fully elastic if } \frac{p_{t+1}}{1+r_{t+1}}=p_{t}-(1-\tau) q_{t} \\
(a-b)_{t+1}^{y} & =\gamma \beta\left(2+\beta-\frac{\eta_{t}}{1-\tau}\right) z-\frac{p_{t+1}}{1+r_{t+1}} g_{t+1} ; \quad a_{t+2}^{o}=\gamma \beta^{2}\left(1+r_{t+1}\right) z
\end{aligned}
$$

\section{Constrained Landlord}

$$
\begin{aligned}
c_{t}^{y} & =\gamma z ; \quad c_{t+1}^{m}=\gamma \beta \frac{\delta_{t+1}}{p_{t}\left(\theta(z)-\frac{1-\tau}{\eta_{t}}\right)} z ; \quad c_{t+2}^{o}=\gamma \beta^{2} \frac{\delta_{t+1}\left(1+r_{t+2}\right)}{p_{t}\left(\theta(z)-\frac{1-\tau}{\eta_{t}}\right)} z \\
h_{t+1} & =\gamma \beta \frac{1}{(1-\tau) q_{t}} z ; \quad s_{t+1}=0 ; \quad g_{t+1}=\gamma \beta \frac{2+\beta-\frac{\eta_{t} \theta(z)}{1-\tau}}{p_{t}\left(\theta(z)-\frac{1-\tau}{\eta_{t}}\right)} z \\
b_{t+1} & =\gamma \beta(1+\beta) \frac{1-\theta(z)}{\theta(z)-\frac{1-\tau}{\eta_{t}}} z ; \quad a_{t+1}^{y}=0 ; \quad a_{t+2}^{m}=\gamma \beta^{2} \frac{\delta_{t+1}}{p_{t}\left(\theta(z)-\frac{1-\tau}{\eta_{t}}\right)} z
\end{aligned}
$$




\section{Proofs of Section 5}

\section{Proof of Proposition 2}

a.i) Existence of LVE as $\tau \searrow 0$.

We rewrite below the aggregate demand for debt and the supply of savings, after imposing the first order condition (25),

$$
\begin{aligned}
B^{L V E} & =\gamma \beta\left\{\begin{array}{c}
\int_{z^{2}}^{z_{1}}\left[(\eta-1+\tau)-(1+\beta)\left(1+\frac{\tau}{\eta \theta(z)-1}\right)\right] z d F(z)+ \\
\int_{z_{2}}^{z_{1}}(2+\beta) \frac{1-\theta(z)}{\theta(z)} z d F(z)-\int_{z_{2}}^{Z}\left(2+\beta-\frac{\eta}{1-\tau}\right) z d F(z)
\end{array}\right\} \\
A^{L V E} & =\gamma \beta^{2}\left\{\begin{array}{c}
\int_{0}^{z_{1}} \frac{1-\frac{\eta}{\eta-(1-\tau)}(1-\theta(z))}{\theta(z)-\frac{1}{\eta}} z d F(z)+\int_{z_{1}}^{z_{2}} \frac{2+\beta}{1+\beta} \frac{1-\frac{\eta}{\eta-(1-\tau)}(1-\theta(z))}{\theta(z)} z d F(z)+ \\
+\int_{z_{2}}^{Z} \frac{\eta}{\eta-(1-\tau)} z d F(z)
\end{array}\right\}
\end{aligned}
$$

A bit of algebra shows that

$$
\lim _{\tau \searrow 0} \frac{\partial B^{L V E}}{\partial \theta}=\lim _{\tau \searrow 0} \frac{\partial A^{L V E}}{\partial \theta}=0
$$

Then, exploiting lemma 7 and the implicit function theorem we learn that $\lim _{\tau \backslash 0} \frac{d r}{d \theta}=0$. Thus, the interest rate that clears the credit market is independent of the value taken by $\theta$ as $\tau$ becomes arbitrarily small. Then, according to lemma 5 and its corollaries, for a LVE to exist, the credit market clearing rate, which we denote by $r_{0}$, must satisfy $r_{0} \geq r^{*}$, or, equivalently, $(1-\tau) \frac{1+r_{0}}{r_{0}}=\eta_{0} \leq \eta^{*}=(1-\tau) \frac{1+r^{*}}{r^{*}}$. As shown in lemma $5, \frac{\partial\left[G^{\max }-S\right]}{\partial \eta}<0$, while some extra simple algebra also shows that $\frac{\partial\left[G^{\max }-S\right]}{\partial \theta}<0$, which together imply that $\frac{d r^{*}}{d \theta}>0$. Thus, the necessary condition $r_{0} \geq r^{*}$ will hold only if $\theta \leq \bar{\theta}$, where $\bar{\theta}$ is implicitly defined in the equality $r_{0}=r^{*}(\bar{\theta})$. Provided $\theta$ falls below that upper bound, monotonicity of the excess demand for credit function (see lemma 5) ensures equilibrium uniqueness, since unique $r$ implies unique equilibrium $\eta, p$ and $q$ (by (25) and (24)).

a.ii) Existence of HVE as $\tau \searrow 0$.

The excess demand function in the credit market now becomes:

$$
B^{H V E}-A^{H V E}=\gamma \beta\left\{\begin{array}{c}
\int_{0}^{z_{1}} \underbrace{\frac{\kappa(z)}{\theta(z)-\frac{1}{\eta}} z d F(z)}_{x_{1}}+\int_{z_{1}}^{z_{2}} \underbrace{\frac{2+\beta}{1+\beta} \frac{\kappa(z)}{\theta(z)} z d F(z)}_{x_{2}}+ \\
\int_{z_{2}}^{Z} \underbrace{\frac{\kappa(z)}{\theta(z)-\frac{1-\tau}{\eta}} z d F(z)}_{x_{3}}
\end{array}\right\}
$$

where $\kappa(z) \equiv(1+2 \beta+\beta r)(1-\theta(z))-\beta$. Below, we show that $\frac{d r}{d \theta}>0$, so that for a sufficiently low $\theta$ there is no positive interest rate that clears the credit market. The complete proof involves several steps:

Step 1. Evaluate the sign of $\frac{d \eta}{d \theta}$. To do this, we totally differentiate the rental market clearing condition,

$$
\int_{0}^{z_{1}} \frac{\eta \theta(z)-(2+\beta)}{\theta(z)-\frac{1}{\eta}} z d F(z)=\int_{z_{2}}^{Z} \frac{2+\beta-\frac{\eta}{1-\tau} \theta(z)}{\theta(z)-\frac{1-\tau}{\eta}} z d F(z)
$$


to find that

$$
\eta_{\theta} \equiv \frac{d \eta}{d \theta}=-\frac{\int_{0}^{z_{1}} \frac{1+\beta}{\left(\theta(z)-\frac{1}{\eta}\right)^{2}} z d F(z)+\int_{z_{2}}^{Z} \frac{1+\beta}{\left(\theta(z)-\frac{1-\tau}{\eta}\right)^{2}} z d F(z)}{\int_{0}^{z_{1}}\left(1+\frac{1+\beta}{\left(\theta(z)-\frac{1}{\eta}\right)^{2}} \frac{1}{\eta^{2}}\right) z d F(z)+\int_{z_{2}}^{Z}\left(\frac{1}{1-\tau}+\frac{1+\beta}{\left(\theta(z)-\frac{1-\tau}{\eta}\right)^{2}} \frac{1-\tau}{\eta^{2}}\right) z d F(z)}<0
$$

Step 2. We next evaluate the sign of partial derivative $\frac{\partial(B-A)}{\partial \theta}$, treating $\eta$ as a (negatively related) function of $\theta$, as juts shown in the previous step. We do this separately for the three terms in the right side of (38).

First, by differentiating $x_{1}$ with respect to $\theta$, we learn that

$$
\frac{\partial x_{1}}{\partial \theta}<0 \Leftrightarrow-\left[(1+2 \beta+\beta r)\left(1-\frac{1}{\eta}\right)-\beta\right]-\frac{\eta_{\theta}}{\eta^{2}} \kappa(z)<0
$$

We next check that the latter sign condition necessarily holds in equilibrium. Since over this range $\theta(z)>\frac{1}{\eta}$, a sufficient condition for that sign condition to be met is that $-\frac{\eta_{\theta}}{\eta^{2}}<1$, or, exploiting (40) above,

$$
\int_{0}^{z_{1}} z d F(z)+\int_{z_{2}}^{Z}\left(\frac{1}{1-\tau}-\frac{1+\beta}{\left(\theta(z)-\frac{1-\tau}{\eta}\right)^{2}} \frac{\tau}{\eta^{2}}\right) z d F(z)>0
$$

As $\frac{1}{1-\tau}>1$, we just check that $\frac{1+\beta}{\left(\theta(z)-\frac{1-\tau}{\eta}\right)^{2}} \frac{\tau}{\eta^{2}}<1$, which suffices to show that $-\frac{\eta_{\theta}}{\eta^{2}}<1$. Some simple algebra reveals that

$$
\frac{1+\beta}{\left(\theta(z)-\frac{1-\tau}{\eta}\right)^{2}} \frac{\tau}{\eta^{2}}<1 \Leftrightarrow \theta(z)>\frac{1-\tau+\sqrt{\tau(1+\beta)}}{\eta}
$$

But over this range, by lemma 3 , the following inequality holds: $\theta(z) \geq \theta_{1}=\frac{2+\beta}{\eta}$. Thus, as $2+\beta>1-\tau+\sqrt{\tau(1+\beta)}$, it follows that $\frac{\partial x_{1}}{\partial \theta}<0$.

Second, for any buyer, we obtain that $\frac{\partial x_{2}}{\partial \theta}<0$.

Finally, following an argument similar to the one employed for renters, it can be shown that

$$
\frac{\partial x_{3}}{\partial \theta}<0 \Leftrightarrow-\left[(1+2 \beta+\beta r)\left(1-\frac{1-\tau}{\eta}\right)-\beta\right]-(1-\tau) \frac{\eta_{\theta}}{\eta^{2}} \kappa(z)<0
$$

As in any interior equilibrium $\theta(z)>\frac{1-\tau}{\eta}$, a sufficient condition for the inequality in the right side above to hold is that $-(1-\tau) \frac{\eta_{\theta}}{\eta^{2}}<1$. A simple manipulation of (40) shows that this last inequality necessarily holds. Thus, $\frac{\partial(B-A)}{\partial \theta}<0$.

Step 3. Using the result in lemma 7, i.e., $\frac{\partial(B-A)}{\partial r}>0$, it directly follows that $\frac{d r}{d \theta}>0$. Let us then define $\underline{\theta}$, as the unique solution for $\theta$ in the credit market clearing condition evaluated at $r=0$. As the interest can not be negative in equilibrium, no HVE exists if $\theta<\underline{\theta}$. Notice that this last result does not hinge on $\tau$ being negligible.

We now turn to the analysis of the upper bound for $\theta$. Let us consider a value for $\theta$, call it $\theta^{+}$, such that $\theta^{+}>\bar{\theta}$, and denote by $\eta^{+}$the price-to-rent ratio that would clear the rental 
market, i.e. the solution to (39) when $\theta=\theta^{+}$. Our claim here is that for such a pair $\left(\theta^{+}, \eta^{+}\right)$ there is a strictly negative excess demand in the credit market when the necessary condition for the existence of a HVE (i.e. $\eta^{+}<(1-\tau) \frac{1+r}{r}$ ) is satisfied. To prove it, we first notice that, as just shown, for $\theta^{+}>\bar{\theta}$ there is no LVE, the reason being that for an interest rate, $r$, satisfying $\eta^{+}=(1-\tau) \frac{1+r}{r}$ there would be a positive excess demand in the rental market and, symmetrically, a negative excess demand in the credit market, as the interest rate that satisfies this last equality would lie strictly above the one that would clear the credit market. ${ }^{23}$ Thus, the following inequality holds as $\eta^{+}=(1-\tau) \frac{1+r}{r}$.

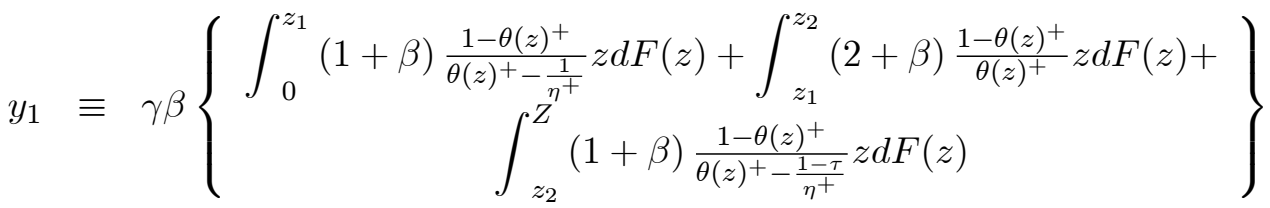

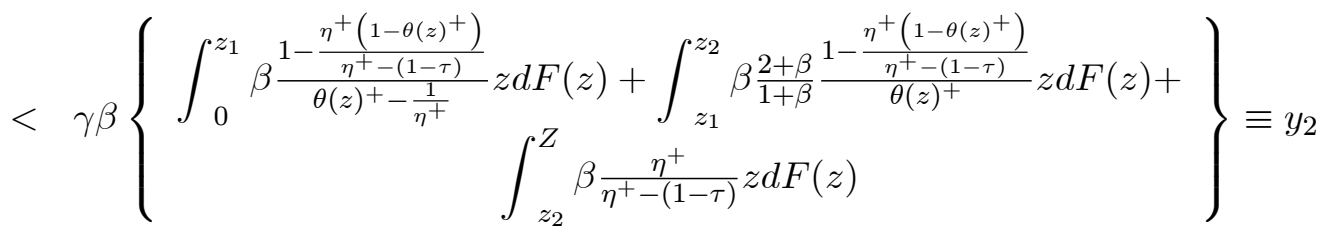

where the first line is the highest demand for funds given a pair $\left(\theta^{+}, \eta^{+}\right)$and the second line is the total supply of funds when $\eta^{+}=(1-\tau) \frac{1+r}{r}$. We next ask whether there exists a $r^{+}$ such that $\eta^{+}<(1-\tau) \frac{1+r^{+}}{r^{+}}$that clears the credit market. The aggregate supply of funds for a vector $\left(\theta^{+}, \eta^{+}, r^{+}\right)$is then given by the first line of the expression below

$$
\begin{aligned}
& y_{3} \equiv \gamma \beta\left\{\begin{array}{c}
\int_{0}^{z_{1}} \beta \frac{1-\left(1+r^{+}\right)\left(1-\theta(z)^{+}\right)}{\theta(z)^{+}-\frac{1}{\eta^{+}}} z d F(z)+\int_{z_{1}}^{z_{2}} \beta \frac{2+\beta}{1+\beta} \frac{1-\left(1+r^{+}\right)\left(1-\theta(z)^{+}\right)}{\theta(z)^{+}} z d F(z)+ \\
\int_{z_{2}}^{Z} \beta \frac{1-\left(1+r^{+}\right)\left(1-\theta(z)^{+}\right)}{\theta(z)^{+-}-\frac{1-\tau}{\eta^{+}}} z d F(z)
\end{array}\right\} \\
& >\gamma \beta\left\{\begin{array}{c}
\int_{0}^{z_{1}} \beta \frac{1-\frac{\eta^{+}(1-\theta(z)+)}{\eta^{+}-(1-\tau)}}{\theta(z)^{+}-\frac{1}{\eta^{+}}} z d F(z)+\int_{z_{1}}^{z_{2}} \beta \frac{2+\beta}{1+\beta} \frac{1-\frac{\eta^{+}\left(1-\theta(z)^{+}\right)}{\eta^{+}-(1-\tau)}}{\theta(z)^{+}} z d F(z)+ \\
\int_{z_{2}}^{Z} \beta \frac{\eta^{+}}{\eta^{+}-(1-\tau)} z d F(z)
\end{array}\right\} \equiv y_{2}
\end{aligned}
$$

where the inequality follows directly from $1+r^{+}<\frac{\eta^{+}}{\eta^{+}-(1-\tau)}$. Combining (42) and (43), we learn that $y_{3}>y_{1}$, and, hence, for $\theta^{+}>\bar{\theta}$ there is no $r^{+}$such that two necessary conditions for the existence of a HVE are simultaneously met, namely credit market clearing and (26).

Finally, equilibrium uniqueness follows from the strict monotonicity of the excess demand function in the rental, credit and housing markets, with respect to $\eta, r$ and $p$, respectively.

b) Coexistence. Straightforward, given previous results.

\section{Proof of lemma 9 (tax experiment)}

As the excess demand for credit is an increasing function of the interest rate around a HVE, we examine the conditions under which there is a negative relationship between the excess demand for credit and the tax rate, since, when this is the case, a rise in $\tau$ may bring a reduction in the excess demand for credit that allows that market to clear at a non-negative rate,as described in the main text. To this aim, we proceed in several steps.

\footnotetext{
${ }^{23}$ Recall, that in a LVE the credit market excess demand function is decreasing in the interest rate as $\tau \searrow 0$.
} 
First step. By totally differentiating the rental market clearing condition (39):, we find that $\frac{d \eta}{d \tau}<0$, i.e.

$$
\eta_{\tau} \equiv \frac{d \eta}{d \tau}=-\frac{\int_{z_{2}}^{Z}\left(\frac{1+\beta}{\left(\theta(z)-\frac{1-\tau}{\eta}\right)^{2}} \frac{1}{\eta}+\frac{\eta}{(1-\tau)^{2}}\right) z d F(z)}{\int_{0}^{z_{1}}\left(1+\frac{1+\beta}{\left(\theta(z)-\frac{1}{\eta}\right)^{2}} \frac{1}{\eta^{2}}\right) z d F(z)+\int_{z_{2}}^{Z}\left(\frac{1+\beta}{\left(\theta(z)-\frac{1-\tau}{\eta}\right)^{2}} \frac{1-\tau}{\eta^{2}}+\frac{1}{1-\tau}\right) z d F(z)}<0
$$

Second step. From (38), it is clear that the effect of a change in $\tau$ may have a positive or a negative effect on the individual net demand for credit, i.e. $b-a^{m}$, depending, among other things, on the initial sign of $b-a^{m} .^{24}$ To deal with this issue, we exploit the following simple result: as the credit market clears, the following sign conditions must hold: $\lim _{z \rightarrow 0} b(z)-$ $a^{m}(z)<0$, and $b(Z)-a^{m}(Z)>0$. To see this, just notice that the numerator of the three terms in the right side of $(38)$, i.e. $\kappa(z)$, are identical functions of $\theta$ and, hence, continuos and monotonically increasing in $z$. Thus, there exists a household (and only one) with income $\widetilde{z}$, such that $0<\widetilde{z}<Z$, and $b(\widetilde{z})-a^{m}(\widetilde{z})=0$, whose individual borrowing limit satisfies: $\widetilde{\theta}=\frac{1+\beta+\beta r}{1+2 \beta+\beta r}$.In the paragraphs bellow we refer to this household as the pivotal household in the credit market and, depending on the identity of this household, we distinguish three possible cases:

Case 1. The pivotal household is a landlord (i.e. $\widetilde{z}>z_{2}$ ). This implies that every renter is a net saver over its life-cycle, that is, $b-a^{m}<0$. Hence, as $\frac{d \eta}{d \tau}<0$, we learn that $\frac{\partial x_{1}}{d \tau}<0$. Regarding the group of buyers, it trivially follows that $\frac{\partial x_{2}}{d \tau}=0$ (which is true regardless of the identity of the pivotal household). Finally, in computing the sign of $\frac{\partial x_{2}}{d \tau}$, we split the total group of landlords into two sets depending on the sign of $b-a^{m}$. As $\frac{d\left(\frac{1-\tau}{\eta}\right)}{d \tau}<0$, the following results are obtained: $\frac{\partial\left(b-a^{m}\right)}{d \tau}>(<) 0$ if $b-a^{m}<(>) 0$. In order to find the sign of the variation of the net demand for credit for the whole group of landlords we first notice that when the credit market clears the following inequalities necessarily hold,

$$
\int_{0}^{z_{1}} \frac{\kappa(z)}{\theta(z)-\frac{1}{\eta}} z d F(z)<0, \text { and } \int_{z_{2}}^{Z} \frac{\kappa(z)}{\theta(z)-\frac{1-\tau}{\eta}} z d F(z)>0
$$

The second inequality above, together with assumption 2 imply that

$$
\int_{z_{2}}^{Z} \frac{\partial\left[\frac{\kappa(z)}{\theta(z)-\frac{1-\tau}{\eta}} z d F(z)\right]}{\partial \tau}<0
$$

Thus, if $\widetilde{z}>z_{2}$, then $\frac{\partial(B-A)}{\partial \tau}<0$.

Case 2. The pivotal household is a constrained buyer (i.e. $z_{1} \leq \widetilde{z} \leq z_{2}$ ). This implies that $b-a^{m}<(>) 0$ for every renter (landlord). Thus, from the the results obtained in the previous case, we learn that here too $\frac{\partial(B-A)}{\partial \tau}<0$.

Case 3. The pivotal household is a renter (i.e. $\widetilde{z} \leq z_{1}$ ). In this case, $b-a^{m}>0$ for every landlord, hence, $\frac{\partial\left(b-a^{m}\right)}{d \tau}<0$. For the group of renters for whom $b-a^{m}<0$, we still obtain $\frac{\partial\left(b-a^{m}\right)}{d \tau}<0$. Now, however, for the remaining renters, i.e. those with $b-a^{m}>0$, the effect is the opposite, i.e. $\frac{\partial\left(b-a^{m}\right)}{d \tau}>0$. Thus, the only scenario in which a rise in $\tau$ does increase the

\footnotetext{
${ }^{24}$ For example, this becomes clear by inspection of the first term in the right side of (38). That is, whether a rise in $\tau$, which, as just shown, lowers $\eta$, shifts $b-a^{m}$ up or downwards obviously depends on the sign of $b-a^{m}$.
} 
excess demand for credit requires the joint fulfillment of the following two conditions: $\widetilde{z} \leq z_{1}$ and

$$
\begin{aligned}
\int_{\widetilde{z}}^{z_{1}} \frac{\kappa(z)}{\left(\theta(z)-\frac{1}{\eta}\right)^{2}} z d F(z)> & -\int_{0}^{\widetilde{z}} \frac{\kappa(z)}{\left(\theta(z)-\frac{1}{\eta}\right)^{2}} z d F(z) \\
& -\int_{z_{2}}^{Z}\left[\frac{\eta}{\eta_{\tau}}+(1-\tau)\right] \frac{\kappa(z)}{\left(\theta(z)-\frac{1-\tau}{\eta}\right)^{2}} z d F(z)
\end{aligned}
$$

We think of this inequality as a very unlikely outcome since market clearing as discussed above requires that the first inequality in (44) holds, i.e.,

$$
\int_{\widetilde{z}}^{z_{1}} \frac{\kappa(z)}{\theta(z)-\frac{1}{\eta}} z d F(z)<-\int_{0}^{\widetilde{z}} \frac{\kappa(z)}{\theta(z)-\frac{1}{\eta}} z d F(z)
$$

That is, while (46) requires a large pool of renters with incomes below $\widetilde{z},(45)$ is basically imposing the opposite, which leads us to believe that the set of parameter and functions specifications that satisfy both inequalities simultaneously may be a very narrow one. In this precise sense, we argue in the main text, that the conditions under which the result of the proposition hold are very general ones. 


\section{References}

Arce, O., and D. López-Salido (2006). Cheap Credit, Banking Competition, and House Prices, mimeo.

Ayuso, J., and F. Restoy (2005). House Prices and Rents in Spain: Does the Discount Factor Matter?, mimeo.

- (2006). "House Prices and Rents: An Equilibrium Asset Pricing Approach", Journal of Empirical Finance, forthcoming.

Baker, D. (2005). The Housing Bubble Fact Sheet, Issue Brief July, CEPR Washington DC.

Berkovec, J., and D. Fullerton (1992). "A General Equilibrium Model of Housing, Taxes, and Portfolio Choice", Journal of Political Economy, 100 (2), pp. 390-429.

Brunnermeier, M. K., and C. Julliard (2005). Housing Prices and Inflation. What Fuels Housing Bubbles?, mimeo.

Caballero, R. J., E. Farhi and M. L. Hammour (2005). "Speculative Growth: Hints from the U.S. Economy", American Economic Review, forthcoming.

Campbell, J. Y., and J. F. Cocco (2005). How Do House Prices Affect Consumption? Evidence from Micro Data, NBER WP No. 11534.

Campbell, J. Y., and R. J. Shiller (1988). "The Dividend-Price Ratio and Expectations of Future Dividends and Discount Factors", Review of Financial Studies, 1 (3), pp. 195-228.

Case, K. E., and R. J. Shiller (2004). Is There a Real Estate Bubble?, Brookings Papers on Economic Activity.

Chambers, M., C. Garriga and D. E. Schlagenhauf (2005). Accounting for Changes in the Homeownership Rate, mimeo.

Duca, J. V. (2005). "Making Sense of Elevated Housing Prices", Southwest Economy, Federal Reserve Bank of Dallas, September-October (5).

European Central Bank (2006). "Assessing House Price Developments in the Euro Area", Monthly Bulletin, February, pp. 55-70.

Fernández-Villaverde, J., and D. Krueger (2005). "Consumption over the Life Cycle: Some Facts from Consumer Expenditure Survey Data", Review of Economics and Statistics, forthcoming.

Flavin, M., and T. Yamashita (2002). "Owner-Occupied Housing and the Composition of the Household Portfolio over the Life Cycle", American Economic Review, 92, pp. 345-362.

Gervais, M. (2002). "Housing Taxation and Capital Accumulation", Journal of Monetary Economics, 49, pp. 1461-1489.

Haurin, D. R., P. H. Hendershott and S. M. Wachter (1997). "Borrowing Constraints and the Tenure Choice of Young Households", Journal of Housing Research, 8, pp. 137-154.

Heathcote, J., and M. Davis (2005). "Housing and the Business Cycle", International Economic Review, 46 (3), pp. 751-784.

Henderson, J. V., and Y. M. Ioannides (1983). "A Model of Housing Tenure Choice", American Economic Review, 73, (1), pp. 98-13. 
Himmelberg, C., C. Mayer and T. Sinai (2005). "Assessing High House Prices: Bubbles, Fundamentals, and Misperceptions", Journal of Economic Perspectives, 19 (4), pp. 67-92.

Iacoviello, M. (2005). "House Prices, Borrowing Constraints, and Monetary Policy in the Business Cycle", American Economic Review, 95 (3), pp. 739-764.

Jeske, K., and D. Krueger (2005). Housing and the Macroeconomy: The Role of Implicit Guarantees for Government Sponsored Enterprises, mimeo.

Kiyotaki, N., and J. H. Moore (1997). "Credit Cycles", Journal of Political Economy, 105 (2), pp. 211-248.

- (2005). "Inside Money and Liquidit", Econometrica, forthcoming.

Krugman, P. (1991). "History versus Expectations", Quarterly Journal of Economics, 106 (2), pp. 651-667.

Leamer, E. (2003). Bubble Trouble? Your Home Has a P/E Ratio Too, UCLA Anderson Forecast Report, June.

Li, W., and R. Yao (2005). The Life-Cycle Effects of House Price Changes, Federal Reserve Bank of Philadelphia, WP No. 05-7.

Linneman, P., and S. M. Wachter (1989). "The Impacts of Borrowing Constraints on Homeownership", AREUEA Journal, 17 (4), pp. 389-402.

Matsuyama, K. (1991). "Increasing Returns, Industrialization, and Indeterminacy of Equilibrium", The Quarterly Journal of Economics, 106 (2), pp. 617-650.

McCarthy, J., and R. W. Peach (2004). "Are Home Prices the Next 'Bubble'?", Federal Reserve Bank of New York Economic Policy Review, December.

Morris, I., and R. Wang. (2006). "A Froth-Finding Mission. Detecting US Housing Bubbles", HSBC Global Research, Macro US Economics, January.

OECD (2006). Economic Outlook, No. 78.

Ortalo-Magné, F., and S. Rady. (2005). "Housing Market Dynamics: On the Contribution of Income Shocks and Credit Constraints", Review of Economic Studies, forthcoming.

Peterson, B. (2004). Aggregate Uncertainty, Individual Uncertainty and Illiquidity: Housing and the Business Cycle, mimeo, Indiana University.

Poterba, J. M. (1984). "Tax Subsidies to Owner-Occupied Housing: An Asset Market Approach", Quarterly Journal of Economics, pp. 729-752.

Stein, J. C. (1995). "Prices and trading volume in the housing market: A model with down-payment effects", Quarterly Journal of Economics, 110 (2), pp. 379-406.

The Economist (2005a). "Still want to buy?", March 3rd.

The Economist (2005b). "A home-grown problem", September 8th.

The Economist (2005c). "Here that hissing sound?", December 8th.

Yang, F. (2005). Consumption along the Life Cycle: How Different is Housing?, Federal Reserve Bank of Minneapolis WP No. 635.

Yao, R., and H. H. Zhang (2005). "Optimal Consumption and Portfolio Choices with Risky Housing and Borrowing Constraints", Review of Financial Studies, 18 (1), pp. 197-239. 


\section{BANCO DE ESPAÑA PUBLICATIONS}

\section{WORKING PAPERS ${ }^{1}$}

0501 ÓSCAR J. ARCE: The fiscal theory of the price level: a narrow theory for non-fiat money.

0502 ROBERT-PAUL BERBEN, ALBERTO LOCARNO, JULIAN MORGAN AND JAVIER VALLÉS: Cross-country differences in monetary policy transmission.

0503 ÁNGEL ESTRADA AND J. DAVID LÓPEZ-SALIDO: Sectoral mark-up dynamics in Spain.

0504 FRANCISCO ALONSO, ROBERTO BLANCO AND GONZALO RUBIO: Testing the forecasting performance of Ibex 35 option-implied risk-neutral densities.

0505 ALICIA GARCÍA-HERRERO AND ÁLVARO ORTIZ: The role of global risk aversion in explaining Latin American sovereign spreads.

0506 ALFREDO MARTíN, JESÚS SAURINA AND VICENTE SALAS: Interest rate dispersion in deposit and loan markets.

0507 MÁXIMO CAMACHO AND GABRIEL PÉREZ-QUIRÓS: Jump-and-rest effect of U.S. business cycles.

0508 LUIS J. ÁLVAREZ, PABLO BURRIEL AND IGNACIO HERNANDO: Do decreasing hazard functions for price changes make any sense?

0509 ÁNGEL DE LA FUENTE AND JUAN F. JIMENO: The private and fiscal returns to schooling and the effect of public policies on private incentives to invest in education: a general framework and some results for the EU.

0510 JUAN J. DOLADO, MARCEL JANSEN AND JUAN F. JIMENO: Dual employment protection legislation: a framework for analysis.

0511 ANA DEL RÍO AND GARRY YOUNG: The determinants of unsecured borrowing: evidence from the British household panel survey.

0512 ANA DEL RÍO AND GARRY YOUNG: The impact of unsecured debt on financial distress among British households.

0513 ADELA LUQUE: Skill mix and technology in Spain: evidence from firm-level data.

0514 J. DAVID LÓPEZ-SALIDO, FERNANDO RESTOY AND JAVIER VALLÉS: Inflation differentials in EMU: The Spanish case.

0515 ISAAC ALFON, ISABEL ARGIMÓN AND PATRICIA BASCUÑANA-AMBRÓs: How individual capital requirements affect capital ratios in UK banks and building societies.

0516 JOSÉ MANUEL CAMPA AND IGNACIO HERNANDO: M\&As performance in the European financial industry.

0517 ALICIA GARCÍA-HERRERO AND DANIEL SANTABÁRBARA: Does China have an impact on foreign direct investment to Latin America?

0518 MAXIMO CAMACHO, GABRIEL PEREZ-QUIROS AND LORENA SAIZ: Do European business cycles look like one?

0519 DANIEL PÉREZ, VICENTE SALAS-FUMÁS AND JESÚS SAURINA: Banking integration in Europe.

0520 JORDI GALÍ, MARK GERTLER AND J. DAVID LÓPEZ-SALIDO: Robustness of the estimates of the hybrid New Keynesian Phillips curve.

0521 JAVIER ANDRÉS, J. DAVID LÓPEZ-SALIDO AND EDWARD NELSON: Sticky-price models and the natural rate hypothesis.

0522 OLYMPIA BOVER: Wealth effects on consumption: microeconometric estimates from the Spanish survey of household finances.

0523 ENRIQUE ALBEROLA, LUIS MOLINA AND DANIEL NAVIA: Say you fix, enjoy and relax: the deleterious effect of peg announcements on fiscal discipline.

0524 AGUSTÍN MARAVALL: An application of the TRAMO SEATS automatic procedure; direct versus indirect adjustment.

0525 ALICIA GARCÍA-HERRERO AND MARÍA SOLEDAD MARTÍNEZ-PERÍA: The mix of international banks' foreign claims: determinants and implications for financial stability.

0526 J. IGNACIO GARCÍA-PÉREZ AND JUAN F. JIMENO: Public sector wage gaps in Spanish regions.

0527 LUIS J. ÁLVAREZ, PABLO BURRIEL AND IGNACIO HERNANDO: Price setting behaviour in Spain: evidence from micro PPI data.

1. Previously published Working Papers are listed in the Banco de España publications calalogue. 
0528 EMMANUEL DHYNE, LUIS J. ÁLVAREZ, HERVÉ LE BIHAN, GIOVANNI VERONESE, DANIEL DIAS, JOHANNES HOFFMANN, NICOLE JONKER, PATRICK LÜNNEMANN, FABIO RUMLER AND JOUKO VILMUNEN: Price setting in the euro area: some stylized facts from individual consumer price data.

0529 TERESA SASTRE AND JOSÉ LUIS FERNÁNDEZ-SÁNCHEZ: Un modelo empírico de las decisiones de gasto de las familias españolas.

0530 ALFREDO MARTÍN-OLIVER, VICENTE SALAS-FUMÁS AND JESÚS SAURINA: A test of the law of one price in retail banking.

0531 GABRIEL JIMÉNEZ AND JESÚS SAURINA: Credit cycles, credit risk, and prudential regulation.

0532 BEATRIZ DE-BLAS-PÉREZ: Exchange rate dynamics in economies with portfolio rigidities.

0533 ÓSCAR J. ARCE: Reflections on fiscalist divergent price-paths.

0534 M. ${ }^{a}$ DE LOS LLANOS MATEA AND MIGUEL PÉREZ: Diferencias en la evolución de los precios de los alimentos frescos por tipo de establecimiento.

0535 JOSÉ MANUEL MARQUÉS, FERNANDO NIETO AND ANA DEL RÍO: Una aproximación a los determinantes de la financiación de las sociedades no financieras en España.

0536 S. FABIANI, M. DRUANT, I. HERNANDO, C. KWAPIL, B. LANDAU, C. LOUPIAS, F. MARTINS, T. MATHÄ, R. SABBATINI, H. STAHL AND A. STOKMAN: The pricing behaviour of firms in the euro area: new survey evidence.

0537 LUIS J. ÁLVAREZ AND I. HERNANDO: The price setting behaviour of Spanish firms: evidence from survey data.

0538 JOSÉ MANUEL CAMPA, LINDA S. GOLDBERG AND JOSÉ M. GONZÁLEZ-MÍNGUEZ: Exchange-rate pass-through to import prices in the euro area.

0539 RAQUEL LAGO-GONZÁLEZ AND VICENTE SALAS-FUMÁS: Market power and bank interest rate adjustments.

0540 FERNANDO RESTOY AND ROSA RODRÍGUEZ: Can fundamentals explain cross-country correlations of asset returns?

0541 FRANCISCO ALONSO AND ROBERTO BLANCO: Is the volatility of the EONIA transmitted to longer-term euro money market interest rates?

0542 LUIS J. ÁLVAREZ, EMMANUEL DHYNE, MARCO M. HOEBERICHTS, CLAUDIA KWAPIL, HERVÉ LE BIHAN, PATRICK LÜNNEMANN, FERNANDO MARTINS, ROBERTO SABBATINI, HARALD STAHL, PHILIP VERMEULEN AND JOUKO VILMUNEN: Sticky prices in the euro area: a summary of new micro evidence.

0601 ARTURO GALINDO, ALEJANDRO IZQUIERDO AND JOSÉ MANUEL MONTERO: Real exchange rates, dollarization and industrial employment in Latin America.

0602 JUAN A. ROJAS AND CARLOS URRUTIA: Social security reform with uninsurable income risk and endogenous borrowing constraints.

0603 CRISTINA BARCELÓ: Housing tenure and labour mobility: a comparison across European countries.

0604 FRANCISCO DE CASTRO AND PABLO HERNÁNDEZ DE COS: The economic effects of exogenous fiscal shocks in Spain: a SVAR approach.

0605 RICARDO GIMENO AND CARMEN MARTÍNEZ-CARRASCAL: The interaction between house prices and loans for house purchase. The Spanish case.

0606 JAVIER DELGADO, VICENTE SALAS AND JESÚS SAURINA: The joint size and ownership specialization in banks' lending.

0607 ÓSCAR J. ARCE: Speculative hyperinflations: When can we rule them out?

0608 PALOMA LÓPEZ-GARCÍA AND SERGIO PUENTE: Business demography in Spain: determinants of firm survival.

0609 JUAN AYUSO AND FERNANDO RESTOY: House prices and rents in Spain: Does the discount factor matter?

0610 ÓSCAR J. ARCE AND J. DAVID LÓPEZ-SALIDO: House prices, rents, and interest rates under collateral constraints.

\begin{tabular}{|c|c|}
\hline BANCODEESPAÑ & $\begin{array}{c}\text { Unidad de Publicaciones } \\
\text { Alcalá, 522; } 28027 \text { Madrid } \\
\text { Telephone +34 } 913386363 \text {. Fax +34 } 913386488 \\
\text { e-mail: Publicaciones@bde.es } \\
\text { www.bde.es }\end{array}$ \\
\hline
\end{tabular}




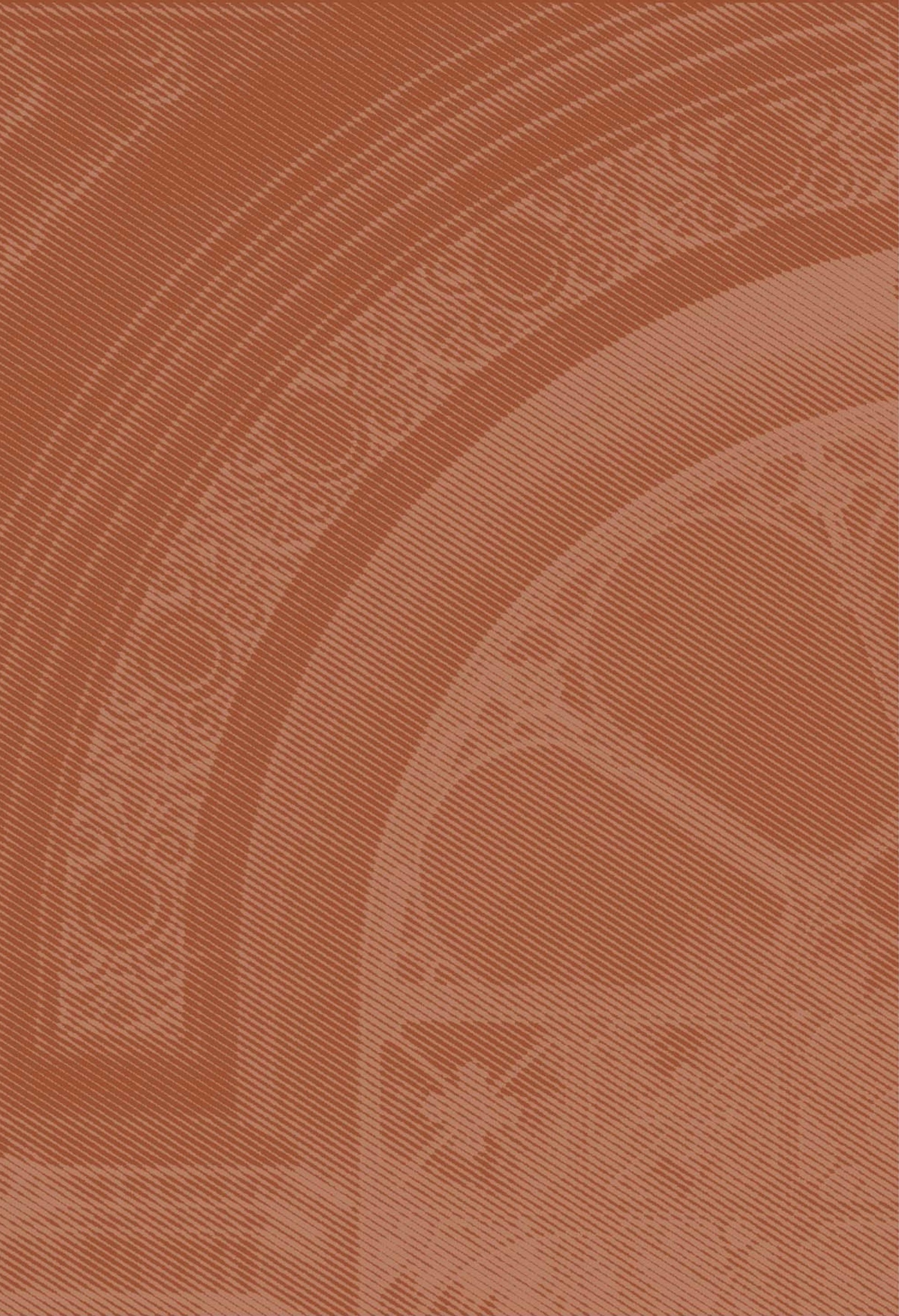

